\title{
Más allá del desarrollo: postdesarrollo y transiciones hacia el pluriverso ${ }^{1}$
}

\section{Beyond Development: Postdevelopment and Transitions towards the Pluriverse}

\author{
Arturo ESCOBAR \\ University of North Carolina at Chapel Hill (Estados Unidos) \\ aescobar@email.unc.edu
}

Recibido: 28 de julio 2011

Aceptado: 10 de noviembre 2011

\begin{abstract}
Resumen
El presente texto constituye el Prefacio a la segunda edición (2011) del ya clásico La invención del tercer mundo: Construcción y deconstrucción del desarrollo (1996). Después de resumir tanto los cambios más importantes ocurridos en el mundo durante los quince años desde la publicación del libro, como los debates y avances en los estudios críticos del desarrollo, se argumenta que ha llegado la hora de reanudar con ahínco el debate sobre el postdesarrollo y las alternativas al desarrollo, como muchos movimientos sociales están de hecho haciéndolo. En un contexto marcado por crisis ecológicas y sociales cada vez más acentuadas, surgen de forma cada vez mas ineludible los discursos sobre la transición a una sociedad otra o a otro modelo civilizatorio. Esta transición podría conducirnos más allá del Universo de la modernidad - la idea de Un Mundo único bajo la hegemonía de ciertas concepciones de la racionalidad, el individuo, la ciencia, el mercado y la economía- hacia un verdadero pluriverso de mundos socio-naturales. Las transiciones anuncian que la globalización no es la última etapa de la modernidad capitalista, sino también el comienzo de mundos nuevos.
\end{abstract}

Palabras clave: postdesarrollo, modernidad, transiciones pluriverso.

${ }^{1}$ Traducción a cargo de Eduardo Restrepo del Prólogo de la reedición del libro Encountering Development (Princeton University Press, 1995, 2011). En 1996 fue publicado por Editorial Norma, Bogotá, como La invención del Tercer Mundo: Construcción y Deconstrucción del desarrollo.

Agradecimientos: Tengo una deuda especial de gratitud con Eduardo Gudynas, director del Centro de Ecología Social en Montevideo, por las esclarecedoras conversaciones sobre el estado de la noción de postdesarrollo sostenidas durante varios días en Chapel Hill (abril 2010). Mi análisis de las transformaciones de América Latina y el pluriverso en la última sección forma parte de un proyecto en curso con Mario Blaser y Marisol de la Cadena, y tiene una gran deuda con su colaboración. También quiero agradecer a Cristina Rojas, Carlos Rosero, Libia Grueso, Charo Mina Rojas, Gustavo Esteva, Enrique Leff, Wendy Harcourt, Dianne Rocheleau, Boaventura de Sousa Santos, Aníbal Quijano, Xochitl Leyva, Eduardo Restrepo y, en Chapel Hill, Larry Grossberg, Michal Osterweil, Joseph Jordan, John Pickles, Eunice Sahle y Mark Driscoll por discusiones sobre algunos de los temas expuestos aquí. La responsabilidad de las ideas que aquí se presentan es, sin embargo, solo mía. Hay muchas otras personas que han influido en mi pensamiento durante los últimos quince años, que no menciono aquí por razones de brevedad. 


\begin{abstract}
The present text constitutes the Preface to the second edition Encountering Development (1995). After reviewing both the most important transformations in the world over the past fifteen years, and the debates in critical development studies during the same period, the author concludes that the time has come to renew the debates on postdevelopment and alternatives to development, as many social movements are actually doing. Given the deepening ecological and social crises, there emerge in undeniable ways discourses about transitions to another type or society or civilizational model. This transition could move us beyond the modern idea of one Universe - One World under the hegemony of certain conceptions of the individual, rationality, economy, science, and the market - towards a genuine pluriverse of socio-natural worlds. These transitions announce that globalization is not only the last stage of capitalist modernity, but also the beginning of something new.
\end{abstract}

Keywords: postdevelopment, modernity, transitions pluriverse.

Referencia normalizada: Escobar, A. (2012) Más allá del desarrollo: postdesarrollo y transiciones hacia el pluriverso. Revista de Antropología Social, 21: 23-62.

SUMARIO: 1. Introducción. 2. Importantes transformaciones mundiales. 3. Evaluación del postdesarrollo. 3.1. Respuestas al postdesarrollo. 3.2. La nueva etnografía de desarrollo. 4. Discursos de la transición: tendencias emergentes. 5. América Latina: ¿hacia un pluriverso?. 6. Conclusión. El fin de la globalización (tal como la conocíamos). 7. Referencias bibliográficas.

Dedico estas páginas a la memoria de Orlando Fals Borda, Julie Graham y Smitu

Kothari, queridos amigos y compañeros en la búsqueda de mundos alternativos.

\title{
1. Introducción
}

Han pasado más de quince años desde que este libro fue publicado por primera vez. Mis esperanzas e intenciones para escribirlo no han cambiado; por el contrario, se han fortalecido desde su publicación. El análisis crítico del desarrollo es tan oportuno y relevante hoy como lo era entonces. En muchas partes del mundo, el 'desarrollo' sigue siendo una importante fuerza social y cultural a la cual enfrentar. Significativas batallas políticas se libran en su nombre, y la vida de muchos y los medios de subsistencia de las personas todavía están en juego en estas batallas. Y decenas de profesionales, aunque quizá en menor número en 2010 en comparación con 1995, en particular en Estados Unidos, ganan su vida en el mundo del desarrollo y activamente debaten el tema en salas de juntas y reuniones del personal de los proyectos de desarrollo en los países donantes y receptores. Por último, pero no menos importante, de nuevo con un entusiasmo un tanto disminuido en los Estados Unidos, son todavía abundantes los académicos - antropólogos, entre ellos - que escriben tesis doctorales y presentan ponencias sobre tal o cual aspecto del desarrollo. Sobre 
todo, el ímpetu político que me movió a escribir sobre 'la invención de desarrollo' y a imaginar una 'era postdesarrollo' a finales de los ochenta y principios de los noventa todavía está muy presente: el hecho es que, como yo lo veo, el 'desarrollo' sigue desempeñando un papel importante en las estrategias de dominación cultural y social, incluso si los académicos podrían tener hoy una visión más matizada de cómo estas estrategias operan, incluso de cómo la gente se apropia del desarrollo para sus propios fines. Por supuesto, mis propias opiniones sobre el tema han cambiado en aspectos importantes, como explicaré en detalle en las páginas que siguen.

La Parte I de este capítulo analiza las transformaciones más significativas en la vida social a nivel global que tienen relación directa con el desarrollo. Estos incluyen cambios en el nivel de la economía política, así como el surgimiento de nuevos actores y ámbitos de acción. La Parte II plantea la cuestión de la relevancia de la noción de 'postdesarrollo'. Esta idea, propuesta inicialmente en la década del noventa, ¿sigue siendo útil, o incluso válida, para transmitir tanto el descentramiento del desarrollo como una reorientación de los imaginarios y prácticas hacia nuevas posibilidades concernientes a Asia, África y América Latina? Si no, ¿puede ser reformulada? ¿debería serlo? ¿cómo? Esta parte examina brevemente las principales tendencias en los estudios críticos del desarrollo de los últimos quince años, incluyendo los novedosos enfoques etnográficos, de economía política y postestructuralistas. La Parte III introduce la idea de 'discursos de la transición'. A raíz de las crisis combinadas de alimentos, energía, clima y pobreza, estos discursos de la transición - particularmente prominentes en las áreas de la ecología, la cultura y la espiritualidad - pueden ser concebidos como marcadores para el postdesarrollo, o como desafíos a la modernidad en general. La Parte IV analiza brevemente algunas propuestas concretas en boga en América Latina, que podrían ser consideradas como una contribución a las prácticas y los discursos de la transición, tales como la lucha sin precedentes en torno a los derechos de la naturaleza y la definición del desarrollo en términos de Buen Vivir (bienestar integral y colectivo). Estas tendencias se ven unidas a cuestiones ontológicas y enactuando potencialmente la idea de avanzar hacia un pluriverso, en el sentido de crear las condiciones para la coexistencia de múltiples mundos interconectados. En esta sección se introduce la idea de pasar del mundo como universo al mundo como pluriverso. La conclusión aboga por el desarrollo de un campo de la transición y de los estudios pluriversales anclados en una visión de la Tierra como un todo viviente siempre emergente. En vez de basarse en la llamada 'globalización', este campo fomentaría el descubrimiento y la imaginación de formas de planetarización en las cuales los seres humanos y otros seres vivos puedan existir en el planeta enriqueciéndose mutuamente.

\section{Importantes transformaciones mundiales}

El mundo ha cambiado enormemente desde mediados de la década del noventa. Desde una perspectiva de los estudios del desarrollo, a mi manera de ver, los cuatro factores más relevantes en esta transformación han sido: primero, el enorme papel asumido por China - y en menor medida la India - en la economía global; segundo, los reajustes en la geopolítica mundial sucedidos a raíz de los ataques contra 
el World Trade Center en Nueva York del 11 de septiembre de 2001 y la posterior invasión de Irak en marzo de 2003; y tercero, el fin del llamado Consenso de Washington, es decir, el conjunto de ideas y prácticas institucionales que aparentemente gobernó la economía mundial desde la década del setenta, más comúnmente conocido como neoliberalismo. El desmantelamiento del socialismo realmente existente y de las economías de planificación centralizada puede ser citado como un cuarto factor, dado que, a pesar de que se inició en la década del ochenta, se convirtió en irreversible en la década del noventa. Estos factores están profundamente relacionados entre sí y están lejos de constituir una secuencia histórica. Primero, los estudios del desarrollo surgieron en China como un campo académico, junto con las preocupaciones inherentes a la liberalización económica seguida por el país desde finales de los años setenta, tales como la desigualdad creciente, la destrucción del medio ambiente, y la exclusión rural, la marginación y la pobreza (véase, por ejemplo, Long, Jingzhong y Yihuan, 2010) ${ }^{2}$. La influencia de China en Asia, África y América Latina ha crecido en paralelo con su poderío económico, y tiene un efecto particularmente pronunciado en el desarrollo en África (Sahle, 2010). Mientras algunos consideran las reformas económicas de China - aunque orquestada por el Estado - como en sintonía con la ideología neoliberal del tipo Consenso de Washington, otros creen que la situación actual se caracteriza por una compleja mezcla de formas económicas, sólo algunas de las cuales se puede caracterizar como liberales o neoliberales (Nonini, 2008; Yang 1999).

En segundo lugar, el surgimiento de una nueva formación geopolítica después de 11 de Septiembre de 2001 es relativamente indiscutible. De importancia clave en este asunto, desde una perspectiva de los estudios del desarrollo, es lo que los académicos de la economía política internacional han llamado la seguralización del desarrollo, es decir, la fusión de las nociones de seguridad de la guerra contra el terrorismo y los marcos de la seguridad humana en el desarrollo, de formas que socavan y limitan el potencial de este último, incluidos en los Objetivos de Desarrollo del Milenio (Sahle, 2010). Tercero, el fin del Consenso de Washington ha sido más evidentemente reflejado en el 'giro a la izquierda' en América Latina, es decir, la ola de gobiernos de izquierda que barrió en la mayoría de los países de la región desde 1998, todos elegidos democráticamente sobre el rechazo explícito del dogma neoliberal de décadas anteriores. Esta tendencia, y sus implicaciones para los estudios

${ }^{2}$ Un programa de doctorado en estudios del desarrollo se inició en la Universidad Agrícola de China en Beijing en 2004. Aunque todavía es el único programa como tal, "hay muchos otros programas de doctorado en otras universidades, donde algunos de los estudiantes pueden hacer una investigación de tesis en estudios del desarrollo, incluso en antropología del desarrollo, en la Universidad de Sun Yat-Sen, por ejemplo. Ahora hay cerca de 30 universidades en China que tienen programas de licenciatura en estudios del desarrollo, aunque la mayoría de ellos son muy prácticos y orientados profesionalmente (similar a los procesos de profesionalización que se describe en su libro, ya que China está tomando el camino del desarrollo de la modernización)" (correo electrónico del profesor Ye Jingzhong de la Universidad Agrícola de China, 8 de agosto de 2010). 
críticos del desarrollo, también se revisará en detalle en las páginas que siguen ${ }^{3}$. Por último, la desaparición del socialismo realmente existente ha tenido un efecto ambiguo sobre los debates del desarrollo. Mientras que, por un lado, con esta caída se ha demostrado que el modelo socialista comparte muchas de las premisas del desarrollo capitalista convencional, apoyando así la idea de postdesarrollo, por el otro, ha contribuido a consolidar el sentido de que 'no hay alternativa', debilitando entonces el debate sobre las alternativas al desarrollo.

Ha habido por supuesto muchos otros cambios importantes en la economía mundial, la geopolítica y la conciencia global, desde la década del noventa, algunos de los cuales se han hecho más visibles en años recientes. La explosión de la conectividad, habilitada por la información digital y las tecnologías de la comunicación - establecida firmemente como un tema académico por la trilogía de Castell sobre la "Sociedad de la Información", publicada en la segunda mitad de la década del noventa (véase especialmente Castells, 1996) - se ha convertido en un punto de referencia obligatorio para muchos trabajos del desarrollo, a pesar de que la mayoría de la gente del mundo todavía carece de acceso a tales bienes y servicios (véase, por ejemplo, Harcourt, 1999). De enorme importancia para la creación de una conciencia global ha sido la crisis ambiental, finalmente traída a la luz pública en los debates nacionales y mundiales por las conferencias sobre el cambio climático mundial y la convergencia científica en torno a los hallazgos del Panel Intergubernamental de Expertos sobre el Cambio Climático (IPCC). Como explicaré más adelante, solo la crisis ecológica tiene el potencial para desestabilizar cualquiera de los marcos de desarrollo existentes en la actualidad si se toma en serio. La crisis económica que comenzó en 2007 que causó el colapso de las instituciones financieras y la burbuja inmobiliaria y la recesión en las bolsas de valores, principalmente en el Norte, tuvo importantes consecuencias a nivel mundial en términos de desaceleración de la actividad económica, disponibilidad de crédito y comercio internacional. $\mathrm{Mu}$ chos países en el Sur Global registraron un aumento significativo de la pobreza y el desempleo y la consiguiente disminución del crecimiento económico (los países de América Latina con gobiernos progresistas son una excepción parcial). Mientras que para algunos críticos la crisis anunciaba el final del capitalismo financiarizado ${ }^{4}$, instituciones como el Banco Mundial se han involucrado en los debates para repensar la globalización después de la crisis, en gran parte basadas en estrategias convencionales para impulsar la competitividad de las exportaciones, en particular para el caso de Áfricas ${ }^{5}$. Está claro que las principales instituciones internacionales

${ }^{3}$ El fin del Consenso de Washington y la aparición de un 'post-consenso de Washington' ha sido analizado, quizás el más famoso en los Estados Unidos, por Joseph Stiglitz (2006). Para la génesis del neoliberalismo en América Latina y otros lugares, ver la excelente elaboración de Naomi Klein (2007).

${ }^{4}$ La idea de que la crisis supone el fin del monopolio del capital financiero ha sido discutida por la crítica marxista en particular; véase, por ejemplo, Bellamy, Foster y Magdoff (2008) y Panitch y Gindin (2008).

${ }^{5}$ Véase, por ejemplo, el informe de una teleconferencia que une cinco países - Ghana, Etiopía, Tanzania, Zambia y los Estados Unidos - patrocinada por el Instituto del Banco Mundial el 29 de marzo de 2010, la segundo de una serie de "debates sobre el desarrollo" a distancia 
de crédito no tienen ideas nuevas para enfrentar los asuntos del desarrollo después de esta crisis. El aumento de los fundamentalismos religiosos en muchas regiones del mundo, incluyendo los Estados Unidos, también debe ser citado como una de las transformaciones más relevantes; en algunos países supone la resistencia a las políticas post 11 de Septiembre y el rechazo de la modernidad al estilo occidental.

En 1995, el Capítulo 5 de Encountering Development trataba sustancialmente sobre los campesinos, las mujeres y el medio ambiente. Mucho ha cambiado desde entonces en relación con estas tres cuestiones, y hoy existen otros actores que no recibieron suficiente atención en el libro, en especial los pueblos indígenas y otros grupos étnicos, tales como las poblaciones afrodescendientes. Incluso si los campesinos han dejado de ser tan centrales para el desarrollo como lo fueron en décadas anteriores, ha habido recientemente un renacimiento de los estudios campesinos y agrarios que incluye novedosas conceptualizaciones de la ruralidad (por ejemplo, evitando la dicotomía rural /urbano, tradicional/moderno); identidades campesinas (tomando en cuenta la influencia de, por ejemplo, las migraciones transnacionales, género y etnicidad); cuestiones previamente no estudiadas o poco estudiadas como los cultivos transgénicos, la conservación y la soberanía alimentaria, y los movimientos sociales campesinos, mucho más allá de la imagen de los años sesenta de los campesinos como sujetos revolucionarios radicales ${ }^{6}$. De ser un tema especial en el desarrollo, como en los discursos de las mujeres en el desarrollo y el desarrollo con orientación de género discutidos en el Capítulo 5, las mujeres han pasado a ocupar un lugar central como sujeto, objeto y conceptualizadoras del desarrollo. Incluso si la mayoría de los trabajos de desarrollo dirigido a grupos de mujeres sigue concentrándose en importantes pero convencionales agendas como el empoderamiento en la economía, la intersección de mujeres, género y desarrollo ha sido un espacio rico para el debate crítico e ideas nuevas sobre el desarrollo durante la última década ${ }^{7}$. El ámbito del medio ambiente tal vez haya visto los cambios más

organizado por el Banco en torno al tema Repensar la globalización después de la crisis. http:// wbi.worldbank.org/wbi/stories/experts-and-policymakers-trade-tips-boost-export-competitiveness-africa (Consultado el 08/10/2010).

${ }^{6}$ Sería imposible hacer justicia aquí a la literatura académica sobre estudios campesinos. La revista Development ha dedicado una serie de números a la alimentación y la agricultura en la última década. Philip McMichael $(2006,2008)$ ha mapeado útilmente algunas de las nuevas agendas que los discursos campesinos plantean en agricultura y alimentación en el centro de las conceptualizaciones de las transformaciones políticas, económicas y ecológicas. Es de destacar que el Journal of Peasant Studies, un icono de los análisis marxistas sobre los campesinos y la 'cuestión agraria' desde principios de los años setenta, recientemente se reestructuró para reflejar algunas de las agendas emergentes. Ver el número especial sobre "Perspectivas críticas en la política rural y el desarrollo", 36 (1), de 2009, y el excelente libro de Wendy Wolford (2010) para nuevos enfoques de los movimientos sociales rurales. Ver también los textos influyentes de la red internacional de organizaciones campesinas y movimientos, Vía Campesina (www.viacampesina. org) y Desmerais (2007) para un estudio sobre esta red.

${ }^{7}$ Una vez más, la literatura aquí es rica y escapa al alcance de este prefacio. Ver Bhavnani, Foran y Kurian (2003) y Harcourt y Escobar (2005) para algunos enfoques recientes. Un tema importante, por ejemplo, anteriormente desconocido o al que se le dio una atención parcial ha sido la política del cuerpo en el desarrollo (ver Harcourt 2010 para un excelente resumen y un 
trascendentales sobre el desarrollo, algunos de los cuales se abordarán más adelante. Baste decir por ahora que el desarrollo se ha convertido en una preocupación central de la ecología política (por ejemplo, Biersack y Greenberg, 2006; Escobar, 2008a) y viceversa, es decir, que las cuestiones ambientales se han convertido cada vez más centrales para el desarrollo, por lo que se ha consolidado el estudio de la "naturaleza en el Sur global" (Greenough y Tsing, 2003).

La visibilidad de los pueblos indígenas y las minorías étnicas como sujetos, objetos y conceptualizadores del desarrollo también ha aumentado dramáticamente. Estos actores están a la vanguardia del trabajo crítico sobre el desarrollo en aspectos importantes, denunciando, por ejemplo, la irracionalidad del desarrollo y la incompatibilidad de muchos proyectos de desarrollo con las cosmovisiones indígenas (ver Mander y Tauli-Corpuz, 2006; Blaser, Feit y McRae, 2004), o al señalar las limitaciones de la Euro-modernidad desde la perspectiva indígena (Blaser 2010). Cuestiones de desarrollo, identidad, territorio y autonomía se han convertido en importantes para el caso de los pueblos indígenas (por ejemplo, de la Cadena y Starn, 2007; Blaser, Feit y McRae, 2010) y grupos afrodescendientes, especialmente en América Latina (Escobar 2008a ; Oslender 2008; Asher 2009; French 2009). La experiencia de las mujeres indígenas en América Latina está proporcionando la base para un 'feminismo descolonial', donde las críticas al etnocentrismo de los discursos feministas modernistas se unieron con el análisis de las formas patriarcales de la exclusión apuntalados por las apelaciones a la tradición o la diferencia cultural (por ejemplo, Hernández, 2008; Suárez Navaz y Hernández, 2008; Hernández 2009; Lugones 2010; Bidaseca 2010; Escobar 2010a ; ver también Radcliffe, Laurie y Andolina, 2009 para una perspectiva feminista relacionada sobre los movimientos indígenas y el desarrollo en los Andes).

Un aspecto de la transformación de las condiciones de desarrollo en los últimos quince años, a menudo no reconocido, aunque de suma importancia, es que las mismas categorías y usos del conocimiento - cuál conocimiento cuenta en el desarrollo, producido por quiénes y con qué fines - han sido objeto de crecientes presiones de muchos lados. Esto afecta a la teoría social en general, en que la cohorte de los interesados en la producción de nuevas teorías se ha expandido mucho más allá de los sujetos habituales en las academias (en gran parte del Norte). Hoy en día un creciente número de investigadores, activistas e intelectuales fuera de la academia están prestando atención a la urgencia de ofrecer interpretaciones alternativas del mundo, incluidas las del desarrollo. En este sentido, las complejas conversaciones que se están dando entre muchos tipos de productores de conocimiento en todo el mundo son en sí mismas una condición esperanzadora para la teoría del desarrollo en la actualidad. Esta urgencia implica no sólo la necesidad de transformar los lugares y el contenido de la teoría, sino su misma forma (Mignolo 2000; Osterweil 2005; Escobar 2008a). Esta tendencia es particularmente aguda en el campo de estudios

sugerente enfoque). Radcliffe, Laurie y Andolina (2009) han analizado útilmente las consecuencias de género del desarrollo y la forma en que se cruzan con movimientos indígenas transnacionalizados de maneras que pueden ser a la vez empoderantes y desempoderantes. 
sobre movimientos sociales (y, como veremos más adelante, en los estudios de la transición), donde la propia investigación de los activistas y su producción de conocimiento se están volviendo centrales para entender lo que los movimientos son, por qué se movilizan y los tipos de mundos que desean constituir. Algunos de los énfasis provienen de enfoques antropológicos y geográficos, incluyendo la difuminación de la frontera entre los mundos y conocimientos académicos y activistas, y de una serie de conceptos y ámbitos de investigación como la etnografía en red, la cartografía de los saberes, la etnografía de las identidades y mundos figurados de los activistas, la investigación activista, partidista y militante; y así sucesivamente ${ }^{8}$. Los académicos en los estudios del desarrollo han estado algo en sintonía con el conocimiento producido por los beneficiarios de los proyectos de desarrollo, aunque en gran parte bajo la forma de 'conocimiento local', sin embargo, todavía no han incorporado estos conocimientos nuevos de manera significativa en su teoría, la toma de decisiones y el diseño de las intervenciones.

Hay un último aspecto de importancia en el libro que me gustaría mencionar antes de seguir adelante: la importancia del discurso económico para la empresa del desarrollo. Este problema, al cual se dedicó el Capítulo 3, apenas fue mencionado en las críticas del libro publicadas entre 1996 y comienzos de la década de dos mil; de hecho, fue ignorado casi por completo. Considero esta ausencia de comentarios no tanto como un signo de la irrelevancia del asunto sino como un índice de la hegemonía naturalizada de una determinada concepción económica del mundo — lo que en el Capítulo 3 llamé 'fabulas de crecimiento y capital', heredada por la economía del desarrollo de la economía política clásica, y en otro lugar (Escobar, 2005) denominé como 'la economía occidental' - un ensamblaje coherente de sistemas de producción, poder y significación que constituyen uno de los pilares más fundamentales de la modernidad. Bien podría ser el caso de que la economía del desarrollo esté casi muerta, y que la economía neoliberal haya sido sacudida hasta la médula por la crisis financiera, pero el imaginario económico en términos de individuos realizando transacciones en los mercados, de producción, crecimiento, capital, progreso, escasez y consumo, continúa sin trabas. Este discurso naturalizado socava muchas,

${ }^{8}$ El trabajo del Grupo de Trabajo de Movimientos Sociales de la UNC en Chapel Hill (www.unc.edu/smwg/) en los últimos cinco años se ha centrado principalmente en esta idea. Ver el número especial de Anthropological Quarterly 81 (1), de 2006, producido colectivamente por el grupo. La idea de que los movimientos sociales deben ser vistos como productores de conocimiento es también el núcleo de otros pocos grupos de investigación en los Estados Unidos y el Reino Unido, incluyendo en la Universidad de Texas en Austin (Antropología), Cornell (Sociología del Desarrollo, por ejemplo, McMichael, ed. 2010), así como en América Latina. El equipo organizado por Xóchitl Leyva en el CIESAS, en San Cristóbal de las Casas, México ha producido varios volúmenes sobre la base de esta afirmación (véase, por ejemplo, Leyva, Burguete y Speed, 2008). Sonia E. Álvarez y sus colegas en la Universidad de Massachusetts, Amherst ha estado al frente de un proyecto con equipos en Estados Unidos y América Latina, en parte centrados en la producción colaborativa del conocimiento. El conocido Colectivo Situaciones en Buenos Aires ha estado produciendo durante una década sus trabajos sobre esta base. Una breve introducción a la literatura sobre esta tendencia se encuentra en Escobar (2008), Casas-Cortés, Osterweil y Powell (2006). 
si no la mayoría de las propuestas actuales para la sostenibilidad y para propender por una era post-carbono. La desnaturalización de la economía es un área de trabajo crítico activo, por ejemplo en la imaginación de economías diversas y en las economías sociales y solidarias más allá de la capitalista o propuestas de decroissance (de-crecimiento). Por otra parte, se puede discernir que a nivel de base, como Esteva dijo provocativamente, "aquellos marginados por la sociedad económica en la era del desarrollo se dedican cada vez más a marginar a la economía" (2009: 20)9 .

\section{Evaluación del postdesarrollo}

La idea de postdesarrollo, con la que la edición de 1995 de este libro terminaba (ver también Escobar 1992; Rahnema y Bawtree,1997), ha demostrado ser controvertida y es importante evaluar su validez en la actualidad. En general, el 'postdesarrollo' surgió de una crítica postestructuralista, es decir, un análisis del desarrollo como conjunto de discursos y prácticas que tuvo un impacto profundo en la manera en que Asia, África y América Latina llegaron a ser consideradas como 'subdesarrolladas' y tratadas como tales. En este contexto, el postdesarrollo estaba destinado a designar por lo menos tres cosas interrelacionadas: primero, la necesidad de descentrar el desarrollo, es decir, de desplazarlo de su posición central en las representaciones y discusiones sobre las condiciones en Asia, África y América Latina. Un corolario de esta primera meta era abrir el espacio discursivo a otras formas de describir esas condiciones, menos mediada por las premisas y las experiencias del 'desarrollo'. Segundo, en el desplazamiento de la centralidad del desarrollo en el imaginario discursivo, el postdesarrollo sugería que efectivamente era posible pensar en el fin del desarrollo. En otras palabras, identificaba alternativas al desarrollo, en lugar de alternativas de desarrollo, como una posibilidad concreta. Tercero, el

\footnotetext{
${ }^{9}$ No voy a ser capaz de discutir aquí el interesante movimiento en torno a la idea de 'décroissance', planteada por primera vez por Serge Latouche (por ejemplo, 2009) en Francia, Joan Martínez Alier (2009) y Jordi Pigem (2009) en Catalunya, y otros en el sur de Europa y América Latina. Hay un grado de heterogeneidad en estas propuestas, dependiendo de si el ímpetu es más político o económico, o si se aplica a los países de altos ingresos (Europa) o los más bajos ingresos, tales como América Latina (correo electrónico con Joan Martínez Alier y Eduardo Gudynas, enero de 2011). El aspecto más relevante de este movimiento para nuestros propósitos, es que las diversas propuestas comparten la crítica al exceso de consumo y al crecimiento basado en la economía y, por ende, la necesidad de cambiar la lógica del desarrollo hacia una menor producción y menor consumo en línea con los límites ecológicos del planeta. En la década del setenta, la Fundación Dag Hammarskjold llevó a cabo un ejercicio muy interesante sobre la base de unir a los países sobredesarrollados como Suecia y los países subdesarrollados como Tanzania en un marco único, como parte de su proyecto, “¿Y ahora qué” y su concepto general de "Otro desarro1lo". Esto podría ser visto como un precursor de las teorías de de-crecimiento. Véase también el proyecto de la Fundación "¿Qué sigue?” (2006-2009) para un excelente ejemplo de pensamiento crítico y alternativo sobre el desarrollo (http://www.dhf.uu.se/). La Red de Objetores de Crecimiento para el Postdesarrollo fue creada en alguna conexión con el proyecto Qué sigue (www. apres-developpement.org). Los debates sobre la economía en América Latina son particularmente activos en el campo de las economias sociales y solidarias, inicialmente promovidas por José Luis Coraggio y Franz Hinkelamert entre otros, véase, por ejemplo, el número especial de América Latina en Movimiento 430 (2008), editado por Coraggio, http://www.alainet.org/publica/430.phtml
} 
postdesarrollo enfatizó la importancia de la transformación de la 'economía política de la verdad', es decir, del orden del conocimiento y poder experto del desarrollo. Con este fin, propone que las ideas más útiles acerca de las alternativas podrían ser obtenidas de los conocimientos y prácticas de los movimientos sociales.

¿Siguen siendo válidas estas afirmaciones hoy en día? Ya hemos visto cómo ciertas transformaciones del mundo han referenciado ambiguamente al postdesarrollo. Por un lado, la consolidación del neoliberalismo en muchas regiones del mundo en la década del noventa hizo la necesidad de las criticas más urgentes, así como lo hizo la creciente conciencia de los costos sociales y ecológicos del 'socialismo de mercado' de China y de la decisión de la India de abrirse a la los mercados mundiales. Por otro lado, sin embargo, la desaparición del socialismo en Europa del Este y, paradójicamente, la llegada al poder de regímenes progresistas de América del Sur transmitió el sentido de que la necesidad del desarrollo era mayor que nunca. Cuestionar el desarrollo en este contexto se vuelve incómodo, aunque, como veremos, algunos movimientos sociales están haciendo exactamente eso, invocando la noción de postdesarrollo en sus críticas. Baste decir por ahora que dado el estado actual de las cosas, a pesar de las ambigüedades señaladas, aún tiene validez las críticas del desarrollo y la idea de imaginar una era del postdesarrollo. Es importante preguntarse, sin embargo, si la idea es válida tal como fue enunciada en la década del noventa, o si es necesario reformularla. Voy a tratar de dar una respuesta a esta pregunta al final de esta sección y, una vez más, al final de la parte IV. Permítanme examinar brevemente por ahora algunas de las respuestas al postdesarrollo.

\subsection{Respuestas al postdesarrollo}

En su formulación más concisa, el postdesarrollo estaba destinado a transmitir el sentido de una época en que el desarrollo ya no sería un principio organizativo central de la vida social. Esto no quiere decir que el postdesarrollo era considerado como un nuevo período histórico al que sus defensores creían que se había llegado, aunque muchos críticos lo vieron así. Sea como fuere, se produjo un rico debate que, paradójicamente, contribuyó a consolidar una posición del 'postdesarrollo' al agrupar a un puñado de autores y libros que los críticos consideraron que, en términos generales, compartían la misma perspectiva ${ }^{10}$. Los análisis y las formas de abogar asociadas con el postdesarrollo se convirtieron en objeto de críticas punzantes y réplicas en la segunda mitad de la década del noventa. Había tres principales objeciones a la propuesta del postdesarrollo. Primero, que al centrarse en el discurso, los proponentes del postdesarrollo pasaban por alto la pobreza y el capitalismo, que son los problemas reales del desarrollo. Segundo, presentaban una visión esencialista del desarrollo, mientras que en realidad hay grandes diferencias entre las estrategias

${ }^{10}$ Estos autores suelen incluir el colectivo de autores representados en el Diccionario del desarrollo (Sachs, ed. 1992) y en The postdeveloment reader (Rahnema y Bawtree, 1997), Vandana Shiva (por ejemplo, 2004), James Ferguson (1990), y Rist (1997). Algunos críticos, por supuesto, han diferenciado los distintos autores. Para una discusión completa y la lista de referencias, ver Escobar (2000, 2007), ver también el análisis completo por Zai (2007), Simon (2007), y McGregor (2009). Lo que sigue es un relato muy resumido de los debates. 
e instituciones de desarrollo, y no se daban cuenta de la impugnación al desarrollo en terreno. Tercero, romantizaban las tradiciones locales y los movimientos sociales, haciendo caso omiso de que lo local también está imbuido en relaciones de poder. Como era de esperar, los proponentes del postdesarrollo respondieron a sus críticos, sugiriendo que las críticas, a su vez, aunque razonables y útiles en muchos aspectos, eran en sí mismas problemáticas.

Para el primer conjunto de críticas, los proponentes postestructuralistas del postdesarrollo respondieron diciendo que este argumento equivale a una defensa ingenua de la realidad. En otras palabras, los críticos del postdesarrollo argumentaban que debido a su enfoque sobre el discurso y la cultura, los postestructuralistas no veían la realidad de la pobreza, el capitalismo y similares. Para los postestructuralistas este argumento tenía validez limitada, ya que se basaba en la suposición (marxista o liberal) que el discurso no es material, desconociendo que la modernidad y el capitalismo son simultáneamente sistemas de discurso y práctica. La segunda crítica era problemática para los autores del postdesarrollo por razones epistemológicas. Parafraseando, los críticos del postdesarrollo decían algo así como: "Ustedes (los defensores del postdesarrollo) representan el desarrollo como homogéneo, mientras que en realidad es diverso. El desarrollo es heterogéneo, controvertido, impuro, híbrido". En respuesta, los teóricos del postdesarrollo reconocen la validez de esta crítica, pero han señalado que su proyecto era diferente: el de analizar la realidad discursiva en general, y no cómo podría haber sido impugnada e hibridizada en el terreno. Se veían a sí mismos menos como 'tratando de encontrar la verdad de las cosas' bajo el mandato de un realismo epistemológico que el postestructuralismo cuestiona, que como intelectuales políticos construyendo un objeto de crítica para el debate y la acción. Por último, los críticos del postdesarrollo cuestionaban a sus partidarios diciendo que idealizaban lo local y las bases. Para los post-estructuralistas y críticos culturales, este comentario era un reflejo del realismo crónico de muchos estudiosos que, invariablemente, etiquetan como romántica cualquier crítica radical de Occidente o cualquier defensa de lo local. Además, los autores postestructuralistas señalaron que la noción realista de cambio social no puede examinar sus propias visiones de lo material, los medios de vida y las necesidades, entre otros (Escobar 2000, 2007; Zai 2007; McGregor 2009).

En tanto avanzaba la primera década del nuevo siglo, el panorama de la teoría del desarrollo dio lugar a una amplia gama de posiciones y al diálogo interparadigmático con sus convergencias (Simon, 2007). Esto podría ser visto como un resultado positivo de los a veces acerbos debates de la década del noventa. Hay una mayor disposición por parte de muchos autores a adoptar constructivamente elementos de las diversas tendencias y paradigmas. Este es particularmente el caso en torno a una serie de cuestionamientos, incluyendo la impugnación del desarrollo, un nuevo acercamiento entre la economía política y análisis cultural sobre cuestiones de desarrollo y economía, el examen de la relación entre el desarrollo y la modernidad, y los nuevos enfoques etnográficos para las políticas y prácticas del desarrollo (abajo). Estas tendencias están produciendo una nueva comprensión de cómo opera el desarrollo y la forma en que se transforma. 


\title{
3.2. La nueva etnografía de desarrollo
}

Recientes enfoques etnográficos para el estudio de los proyectos de desarrollo han recibido especial atención en los debates sobre el desarrollo. Estos enfoques sugieren que la investigación etnográfica podría ser utilizada para arrojar nueva comprensión sobre cómo operan las políticas, y que este conocimiento podría ser utilizado para vincular de forma constructiva la política social, la política de la academia y las aspiraciones de los pobres. Como el principal defensor de este enfoque lo planteó,

\begin{abstract}
"Aquí la labor de la antropología consiste en centrarse en las relaciones sociales que sustentan el trabajo conceptual, para mostrar cómo las racionalidades del desarrollo nunca están libres de contextos sociales al viajar de un sitio a otro, cómo se inician en relaciones sociales, instituciones y comunidades de expertos, viajan con un equipaje no revelado, son transformadas medida que se despliega en otros mundos sociales/institucionales - tal vez a través del interés de colaboradores locales, contrapartes oficiales o mediadores - y es recolonizado por la política de manera que genera efectos complejos y no intencionales" (Mosse, 2008: 120, 121).
\end{abstract}

Estas investigaciones implican una especie de hiper-etnografía que le permite al etnógrafo ver la totalidad de las redes del desarrollo, investigar en profundidad los principales sitios con sus respectivos actores, bagajes culturales, y la apropiación práctica de las intervenciones por los grupos locales. El resultado, según se argumenta, debe dar a los teóricos y practicantes una explicación más matizada de cómo opera el desarrollo en tanto un proceso multi-escala que es constantemente transformado y desafiado. La esperanza es que, dada la realidad del desarrollo, el etnógrafo crítico podría aclarar las condiciones para proyectos más exitosos, tal vez incluso una más eficaz apropiación popular de los proyectos ${ }^{11}$.

Al examinar más a fondo las redes de actores que componen los proyectos de desarrollo, esta tendencia ha contribuido a desesencializar el desarrollo y, por lo tanto, indirectamente, a la teorización del postdesarrollo. Al hacerlo, sin embargo, estos enfoques han solucionado algunos problemas, pero crean nuevos rompecabezas. La cuestión de la agencia ha quedado indicada pero confusa (dado que todo tiene agencia, incluyendo objetos tales como textos, ¿cómo se puede diferenciar entre diferentes tipos de agencia?). De manera similar con la proliferación de la conectividad (todo está conectado con todo, pero ¿cómo las cosas están conectadas de manera diferente? ¿qué tipo de conexiones son políticamente poderosas, o comprometidas?). Los asuntos de la diferencia, además, son a menudo puestos entre paréntesis, en el sentido de que no hay ninguna explicación clara de lo que ocurre con lo que es auténticamente emergente, o como entender esas experiencias que no se puede leer con las categorías del presente, incluidas las de las ciencias sociales modernas ${ }^{12}$. A menos que se traten estas preguntas de manera eficaz, a mi parecer, algunas de las posiciones adoptadas por las etnografías recientes del desarrollo y

${ }^{11}$ Véase especialmente Mosse (2005), Mosse y Lewis (2005) y Li (2007).

${ }^{12}$ En otro lugar (Escobar 2008b) analicé estos problemas en términos de cuatro estrategias problemáticas qe afectan gran parte de la literatura de las ciencias sociales que enfatiza un enfo- 
del Estado corren el riesgo de caer en lo que Boaventura de Sousa Santos (2007) ha llamado una 'hermenéutica del cinismo', dado que nada de lo que ningún actor haga puede llegar a ser un reto importante para lo que existe o producir un pensamiento significativamente diferente. Por otra parte, se ha argumentado que estos trabajos evaden un compromiso serio con los deseos por el desarrollo y con las aspiraciones de los pobres (de Vries, 2008). De hecho, es el caso de que las etnografías del desarrollo han hecho mucho por visibilizar las comunidades transnacionales de expertos cuyas formaciones, intereses, gustos y objetivos económicos y políticos coinciden lo suficiente para mantener las actor-redes del desarrollo operando, a menudo bien aceitadas. Sin embargo, esta conciencia tiene que ir acompañada de una urgencia renovada por una crítica del hecho de que "en cada etapa, los especialistas en nuevos campos son llamados a crear su propio papel en la historia de la aplicación global de la experticia" (Lohmann, 2006: 150). Estos expertos transnacionalizados de clase media, tanto del Norte global como del Sur global, difunden una racionalidad y sentido común normalizados, con importantes consecuencias culturales y políticas.

Hay otras líneas de respuesta a las nuevas etnografías derivadas de la economía política y de las perspectivas postestructuralistas. Una característica común de estos trabajos es un claro énfasis en el poder y la dominación en comparación con muchos de los enfoques de red. Mediante la combinación de los estudios críticos de administración y el postdesarrollo, por ejemplo, un grupo de autores argumentan que las aplicaciones de ideas de gerencia (management) al desarrollo despliega nuevas prácticas políticas, como la tendencia etnográfica que acabamos de examinar acertadamente subraya, pero que esto no quiere decir que estas prácticas dejen de funcionar como instrumentos de dominación (Dar y Cooke, 2008). Un punto de vista relacionado considera que el cambio en el discurso de la ayuda a la 'buena gobernanza, los 'partnerships' (alianzas o colaboraciones)' y el 'apropiarse' de los proyectos no sólo da expresión "a la voluntad profunda de civilizar, sino que reafirma los valores sagrados del campo de la ayuda al desarrollo: la modernidad, la racionalidad y la neutralidad política" (Gould, 2005: 69). Para parafrasear: escarbe en un sistema de administración, y encontrará una lucha cultural y de poder, aunque sea expresada en términos de la acción racional. Como Rojas y Kindornay concluyeron en su análisis de las políticas de gobernar el desarrollo,

"Bajo el diseño global del desarrollo, la incapacidad para mejorar ha obligado al
constante reenvasado de prescripciones y técnicas de gobierno en un intento de
salvar las políticas y prácticas convencionales. A pesar de las críticas desde abajo
y más de cincuenta años de éxitos menores y numerosos fracasos, la corriente con-
vencional del desarrollo sigue siendo formulada a través de lenguajes y prácticas
renovados; aunque nuevos paradigmas y modas surgen, el desarrollo sigue encar-
nando últimamente un imaginario global de modernización (de próxima publica-
ción: 13).

que disperso a lo social, como la teoría del actor-red: agentividad radical, conectividad radical, contextualidad radical e historicidad radical. 
Basándose en la teoría postcolonial, Sinha (2008) sitúa los esquemas del desarrollo dentro de regímenes transnacionales en ascenso, para el caso de la India, desde principios del siglo XX, unido a proyectos ético-políticos burgueses, el poder del Estado y la racionalidad moderna en una complejo geo-cultura del desarrollo en el que la subalternidad en sí es también redefinida. Esta visión resuena con la afirmación de Bebbington (2004), que los regímenes de desarrollo, incluidas las ONG, deben ser considerados como una contribución a la creación de geografías desiguales de la pobreza y subsistencia. Una de las pruebas más elocuentes de tal desigual geografía es el caso del total desmantelamiento de un sistema ancestral de riego y cultivo del arroz en Bali, en nombre del desarrollo moderno, a partir de la Revolución Verde en los años sesenta. Realizada desde la perspectiva de los sistemas complejos adaptativos, esta investigación etnográfica constituye una prueba convincente de la destrucción casi total de un sistema que había logrado un 'orden perfecto' funcional a través de siglos de auto-organización. Esta destrucción resultó en una profunda crisis social y ambiental para toda la población (Lansing, 2006). Estudios como este contribuyen a mostrar las limitaciones de las hiper-etnografías del desarrollo mencionadas anteriormente.

Si bien los enfoques de red diversifican las preguntas de la agencia, a menudo su desventaja es la imposibilidad de imaginar implicaciones prácticas radicales. Este riesgo es mantenido a raya por trabajos que llevan a cabo la investigación desde la perspectiva de, y a menudo en colaboración con, comunidades particulares. Si bien estos enfoques pueden ser considerados como más convencionales en los juegos de verdad de la academia, esto no quiere decir que los análisis son menos matizados, por el contrario, ganan en profundidad y posicionamiento político. Al examinar las redefiniciones del desarrollo local por parte de grupos indígenas en el suroeste de Colombia, por ejemplo, Gow (2008) sostiene que estos grupos producen una especie de 'contra-desarrollo' a través del cual los proyectos de planificación, de educación y de salud se reorientan hacia un distintivo proyecto cultural y político en un intento por crear una modernidad indígena, donde las preocupaciones por la diferencia cultural - y la autonomía para cambiar la cultura - se combinan con las de justicia social. Arce y Long (2000) también han esbozado útilmente un proyecto de pluralización de la modernidad, centrándose en la contra-labor desplegada en el desarrollo por grupos locales. La contra-labor puede desesencializar los productos occidentales de su poder superior, o contribuir al empoderamiento de la autodefinición de un grupo, incluso a medida que cambia. La contra-labor y el contra-desarrollo, por lo tanto, pueden ser considerados como apuntando a formas de desarrollo alternativo, sino también como alimentando los puntos de vista del postdesarrollo. Esto no significa negar los deseos y esperanzas del desarrollo y la modernidad que muchas personas en el mundo han adoptado como resultado de su encuentro con el desarrollo y la modernidad. Como de Vries (2007) ha señalado estos deseos son reales, aunque banalizados y cada vez más difíciles de alcanzar por los proyectos de desarrollo. Ellos son ignorados por la mayoría de las críticas, incluidas la postestructuralista, y deben abordarse de frente en cualquier enfoque crítico de los estudios del desarrollo (de Vries, 2007; ver también Gow, 2008). 
Una manera de salir de este aparente callejón sin salida es investigar la forma en que, por ejemplo, los pueblos indígenas se posicionan críticamente 'en el camino del desarrollo', la forma en que elaboran 'planes de vida' que responden tanto a los procesos modernos/globales como a lógicas culturales basadas-en-lugar de larga data. Aunque los planes de vida pueden incorporar estratégicamente oportunidades ofrecidas por el desarrollo, socavan las pretensiones de universalización del desarrollo y pueden contribuir a luchas no-hegemónicas (Blaser, 2004). Esta dinámica se encuentra en juego en el campo del desarrollo energético en algunas naciones indígenas de América del Norte, donde las comunidades orientan sus decisiones entre tecnologías convencionales y emergentes de maneras que implican repensar significativamente las políticas culturales de desarrollo energético (Powell, 2010). Una vez más, estos trabajos no plantean una simple posición vis à vis el desarrollo. Determinar lo que localmente se entiende por 'desarrollo' es siempre una cuestión compleja. Esta cuestión es abordada por Medeiros (2005) en el marco latinoamericano de la colonialidad del poder y del conocimiento. Expresiones locales del deseo de desarrollo, como ella lo muestra en su análisis etnográfico de los proyectos de desarrollo rural en el altiplano boliviano financiado por la Agencia Alemana para el Desarrollo (GTZ), necesitan ser entendidas en el contexto de la compleja historia de varios cientos de años de discriminación, incluyendo la experiencia de las promesas hechas pero nunca cumplidas desde la independencia. En ausencia de este análisis, y a pesar de las buenas intenciones, los proyectos de desarrollo a menudo terminan reproduciendo viejas asimetrías de poder/conocimiento. Como Medeiros lo muestra, los campesinos indígenas tienen su propia comprensión situada del desarrollo, la cual articula su experiencia histórica de la modernidad y la colonialidad. La noción local de desarrollo incluye la adquisición de aquellas herramientas de los sistemas de conocimiento dominante que podrían darles la posibilidad de implementar un futuro viable. La discusión local sobre el desarrollo no es sólo sobre el desarrollo en sí, sino sobre la historia y la cultura — sobre el Estado, la ciudadanía, la diferencia, el conocimiento y la explotación- Se trata de la posición de las comunidades dentro del sistema mundo moderno colonial ${ }^{13}$. Esta dinámica se revela a menudo en los trabajos ubicados en la intersección entre las redes transnacionales del desarrollo y las luchas de los movimientos sociales, particularmente en los Andes contemporáneos donde los asuntos de la historia, la cultura, la justicia y la diferencia, y las nunca demasiado simples interconexiones entre todos ellos, se acentúan (por ejemplo, Andolina, Laurie y Radcliffe, 2009).

Entonces, ¿qué podemos decir sobre la noción de postdesarrollo después de esta revisión quizá demasiado apresurada y parcial de las tendencias académicas? Una respuesta satisfactoria a esta pregunta habrá de esperar a la última sección de este capítulo. Hay algunas cuestiones que se pueden destacar por ahora, sin embargo, en

${ }^{13}$ Como concluye Medeiros (2005), el problema que las agencias de desarrollo necesitan enfrentar no es tanto que la población local esté fuera de la modernidad, sino las formas específicas en que han sido producidas por la modernidad - es decir, la colonialidad del poder y la diferencia colonial - Es su experiencia histórica de la modernidad lo que configura sus visiones, desconfianza, y esperanzas. 
relación con la utilidad de la noción en la actualidad. Creo que el núcleo de la noción sigue siendo válido, es decir, la necesidad de descentrar el desarrollo como un descriptor social, el cuestionamiento de las prácticas de conocimiento del desarrollo, y la crítica inmanente del postdesarrollo a las ideas de crecimiento, progreso y modernidad. Sin embargo, estos contenidos han sido cualificados y enriquecidos por los debates académicos en los últimos quince años. Las etnografías del desarrollo, por ejemplo, han dado una visión más detallada de cómo opera el aparato del desarrollo. Trabajos centrados en actores nuevos (por ejemplo, los pueblos indígenas, el ambiente) han resaltado cómo estos actores desafían los regímenes de verdad desarrollistas. Al hecho general de la dominación que la crítica discursiva de la década de los años noventa destacó, la economía política y análisis postestructuralistas han añadido una comprensión más compleja de cómo funciona la dominación a través de determinadas prácticas del capitalismo y del Estado.

Dicho esto, una de las principales consecuencias del postdesarrollo queda aparentemente sin solución: la noción de alternativas al desarrollo. No sólo el proyecto del desarrollo sigue viento en popa, sino que parece haberse vuelto más fuerte desde mediados de la década del noventa. Como Gustavo Esteva (2009:1), uno de los críticos más lúcidos y persistentes del desarrollo, planteó en su análisis más reciente: "el desarrollo fracasó como un esfuerzo socio-económico, pero el discurso del desarrollo aún contamina la realidad social. La palabra permanece en el centro de una poderosa pero frágil constelación semántica”. A pesar de una serie de crisis, los discursos y los retos político-culturales concretos parecen jugar a favor de mantener vivo el imaginario de las alternativas al desarrollo. A esta posibilidad dedicaré el resto de este capítulo.

\section{Discursos de la transición: tendencias emergentes}

Los argumentos sobre la necesidad de una profunda transición de época son un signo de los tiempos, reflejan la profundidad de la crisis contemporánea. Sin duda, hablar de la crisis y las transiciones tiene una larga genealogía en Occidente, ya sea en forma de 'crisis de la civilización', las transiciones hacia y desde el capitalismo, las visiones apocalípticas del fin del mundo, repentinas transformaciones religiosas o tecnológicas, o relatos de ciencia ficción. Este no es el lugar para analizar esta genealogía ${ }^{14}$, sin embargo, me parece que es posible argumentar que los discursos de la transición (DsT) están apareciendo hoy con particular riqueza, diversidad e intensidad hasta el punto de que un verificable campo de 'estudios de la transición' puede ser planteado como un ámbito académico-político emergente. Estudios de la transición y el activismo de la transición son ahora un hecho de nuestro tiempo. Notablemente, como incluso un mapa superficial de los DsT sugiere, quienes escriben sobre el tema no se limitan a la academia; de hecho, los pensadores de los DsT más visionarios se encuentran fuera de ésta, aunque en la mayoría de los casos se

${ }^{14}$ Esta sección tendrá un desarrollo pleno en un pequeño libro en curso, tentativamente titulado El fin de la globalización (tal como la conocíamos): diseños para el pluriverso. El libro también incluye un marco para el diseño ontológico. 
enganchan con las corrientes críticas en la academia. Los DsT están apareciendo de una multiplicidad de sitios, principalmente de los movimientos sociales en todo el mundo, de algunas ONG de la sociedad civil, de algunos paradigmas científicos emergentes, y de los intelectuales con vínculos significativos con las luchas ambientales y culturales. Los DsT ocupan un lugar destacado en varios campos, incluidos los de la cultura, la ecología, la religión y la espiritualidad, la ciencia alternativa (por ejemplo, los sistemas vivos y la complejidad), la economía política, y las nuevas tecnologías digitales y biológicas. Sólo los tres primeros se abordarán en lo que sigue. Pero antes realizaré una observación general sobre el concepto de transición.

Como ha señalado recientemente Mezzadra, "el problema de la transición resurge en cada momento histórico cuando las condiciones de la traducción tienen que ser establecidas de nuevo" (2007: 4). Lo que quiere decir con la traducción es el proceso mediante el cual experiencias histórico-culturales diferentes, y a menudo contrastantes, se hacen mutuamente inteligibles y conmensurables; esto ha sucedido en la historia reciente a través de la imposición de los códigos culturales de la modernidad capitalista en una escala cada vez más global. Este proceso, como Mezzandra sugiere, ya no es aceptable; al contrario se hace necesario un nuevo tipo de traducción heterolingüe en el cual las nuevas comunalidades se construyan precisamente a partir de diferencias inconmensurables. Como argumentaré aquí, hay algunas diferencias radicales en la actual ola de los DsT en comparación con las del pasado más reciente. Dos de estas diferencias, subrayadas por Boaventura de Sousa Santos (2007), son que los procesos de transición/traducción no pueden ser orientados por una teoría general, de hecho, la única teoría general posible, como él dice para consternación de buena parte de la teorización de la izquierda, es la imposibilidad de una teoría general. El segundo, y relacionado, aspecto es que hoy en día está más claro que la traducción siempre implica complejos procesos epistemológicos -inter-culturales e inter-epistémicos-, que requieren a su vez un tipo de justicia cognitiva que no ha sido reconocido. Un tercer elemento se insinúa a sí mismo, y es que la transición/traducción implica ontologías múltiples; es decir, cuando es concebida radicalmente, la transición implica pasar de la comprensión moderna del mundo como universo al mundo como pluriverso (sin pre-existentes universales) o, como voy a plantear a continuación, desplazarse de un paradigma de la 'globalización' a uno de la 'planetarización'. Si el primero privilegia la integración económica y cultural y la homogeneización bajo una serie de principios universales (eurocéntricos), la última aboga por una comunicabilidad entre una multiplicidad de mundos culturales en la base de un entendimiento ecológico y político compartido (Santos, 2007). Sucintamente, la transición hacia el pluriverso requiere un concepto más amplio de la traducción que incluye las dimensiones ontológica y epistémica.

Un sello de los DsT contemporáneos es el hecho de postular una transformación radical cultural e institucional: de hecho, una transición a un mundo totalmente diferente. Esto es diversamente conceptualizado en términos de un cambio de paradigma (por ejemplo, GTI 2002), un cambio de modelo de civilización (por ejemplo, Shiva 2008; los movimientos indígenas en América Latina, ver más abajo), la aparición de un nuevo orden, un salto cuántico (Laszlo, 2008), el surgimiento de una 
nueva cultura holística, o incluso de la llegada de una era completamente nueva más allá de la edad moderna dualista, (por ejemplo, Macy, 2007; Goodwin, 2007), reduccionista (por ejemplo, Kauffman, 2008) y económica (por ejemplo, Schafer, 2008). Este cambio es a menudo visto como inminente o como que ya está sucediendo, aunque la mayoría de los DsT advierten que los resultados no están de ninguna manera garantizados. Citemos unas pocas declaraciones sobre la transición:

"La transición global ha comenzado —una sociedad planetaria se configurará en las próximas décadas - . Pero el resultado está en cuestión... Dependiendo de cómo se resuelvan los conflictos ambientales y sociales, el desarrollo global puede bifurcarse en caminos radicalmente diferentes. En el lado oscuro, es muy fácil de imaginar un futuro sombrío de empobrecimiento de las personas, las culturas y la naturaleza. De hecho, para muchos esta posibilidad ominosa parece la más probable. Pero no es inevitable. La humanidad tiene el poder de prever, elegir y actuar. Aunque pueda parecer improbable, una transición hacia un futuro de vidas enriquecidas, solidaridad humana y salud del planeta es posible" (The Great Transition Initiative [Iniciativa de la Gran Transición], GTI 2002: ix).

"La vida en nuestro planeta está en problemas. Es difícil ir a alguna parte sin ser confrontado por las heridas de nuestro mundo, la ruptura del tejido de la vida ... Nuestro planeta nos está enviando señales de socorro, que son tan constantes que ahora parecen casi normales ... Estas son las señales de advertencia de que vivimos en un mundo que puede llegar a su fin, al menos como un hogar de la vida consciente. Esto no quiere decir que $v a$ a terminar, sino que puede terminar. Esta misma posibilidad lo cambia todo para nosotros. ... Esto está sucediendo ahora en formas que convergen para poner en cuestión el fundamento mismo y la dirección de nuestra civilización. Una revolución global está ocurriendo... Muchos la están llamando el Gran Giro" (Macy, 2007: 17, 140).

"Si aceptamos la muerte de nuestro propio cuerpo humano, tal vez podamos empezar a aceptar la eventual muerte de nuestra propia civilización... El calentamiento global es un síntoma temprano de la muerte de nuestra civilización actual... Se puede atenuar este proceso, deteniendo [el sobreconsumo] y estando alertas, pero la única manera de hacer esto es aceptar la muerte eventual de esta civilización" (Hanh, 2008: 57).

Aunque lo que estos autores entienden por civilización no es necesariamente lo mismo, estos pronunciamientos en términos generales se refieren al modelo cultural que ha prevalecido en Occidente durante los últimos siglos: el modelo de 'crecimiento industrial' (Macy, 2007), un modo de vida centrado en el consumo (Hanh, 2008), con sus ideologías reinantes de materialismo, capitalismo de mercado y progreso (GTI). Y aunque resulta sorprendente encontrar un venerado maestro budista (Thich Nhat Hanh) que nos pide meditar sobre la muerte de la civilización actual, muchas de las visiones más seculares enfatizan una profunda transformación de los valores. De hecho, los DsT más imaginativos vinculan aspectos de la realidad que se habían mantenido separados en las imaginaciones anteriores de la transformación social: ontológicos, culturales, político-económicos, ecológicos y espirituales. Estos 
son reunidos por una profunda preocupación por el sufrimiento humano y el destino de la vida misma. Por 'vida' me refiero al conjunto interminable de formas y entidades que componen el pluriverso - desde lo biofísico a lo humano y lo sobrenatural-y los procesos por los que vienen a ser. Esto va claramente más allá de una preocupación por la 'naturaleza', aunque la mayoría de los DsT están atravesados por los temas ecológicos; no podía ser de otra manera, dado que son motivados por, y responden a, las crisis interrelacionadas de energía, alimentos, clima y pobreza.

Comunes a muchos de los discursos de la transición, y tal vez mejor ejemplificado por GTI, es que la humanidad está en un punto de bifurcación y entrando en una fase planetaria de la civilización, como resultado de la expansión acelerada de la era moderna de las últimas décadas, un sistema global tomando forma, fundamentalmente diferente de etapas históricas anteriores. El carácter de la transición dependerá de cual visión del mundo prevalece. La clave es anticiparse a los despliegues de las crisis, imaginar futuros alternativos y tomar las decisiones adecuadas. El GTI distingue entre tres visiones del mundo o formas de pensar - evolucionaria, catastrófica y transformacional - con sus correspondientes escenarios globales: mundos convencionales, barbarización y la Gran Transición $(\mathrm{GT})^{15}$. Sólo la última promete soluciones duraderas a los desafíos de la sostenibilidad, pero requiere cambios fundamentales en los valores, así como nuevos arreglos socio-económicos e institucionales. El paradigma de la GT redefine el progreso en términos no-materiales de la realización humana. Enfatiza la interconectividad e imagina una producción desmaterializada, la disociación de bienestar del consumo y el cultivo de nuevos valores (por ejemplo, la solidaridad, la ética, la comunidad, el significado). Su objetivo es posibilitar una era de energía renovable. La GT implica, sobre todo, un cambio de

${ }^{15}$ Brevemente, el escenario 'mundos convencionales' se basa en las fuerzas del mercado (los mercados globales impulsando el desarrollo global) o en la reforma política (el gobierno comprehensivo y la acción internacional para la reducción de la pobreza y la sustentabilidad ambiental), o una combinación de ambos. Estos escenarios podrían alcanzar una cierta moderación de las tendencias actuales, pero no pueden reunir la voluntad política para hacer que sus objetivos declarados sean viables. Del mismo modo, el segundo escenario, la 'barbarización', tiene dos variantes: el 'colapso' (colapso institucional) y el 'mundo fortaleza' (apartheid global con la vasta mayoría del mundo excluido). Escritos de la GTI incluyen ideas sobre cómo trabajar hacia la transición a través de cambios institucionales y culturales concretos. La GTI se basa en el influyente análisis de escenarios y puntos de ramificación elaborado por el ecologista argentino Gilberto Gallopín. La GTI tiene actualmente su sede en el Instituto Tellus dirigido por Paul Raskin. Ver GTI (2002), y el sitio web del proyecto, Iniciativa de la Gran Transición: http://www. gtinitiative.org/. Muchas de estas concepciones se basan en un marco de sistemas socio-naturales complejos interactuantes desde la comunidad al nivel planetario. Mientras que los escenarios más convencionales implican una teleología clara, el tipo de escenarios de la GTI se construyen sobre principios dinámicos no-lineales como parte del concepto de transición. Esto incluye los conceptos de bifurcación y macro-saltos (véase, por ejemplo, Goodwin 2007; Laszlo 2008). Hay que decir que a pesar de su carácter global, la mayoría de los DsT todavía tiene la experiencia moderna occidental como punto de referencia y motor de cambio. Si bien esto tiene sentido dadas las hegemonías modernas, los DsT críticos requieren la incorporación de manera más explícita de las experiencias y las dinámicas de las socio-naturalezas en el Sur global. 
valores dirigido hacia una visión global alternativa, que sustituye el 'capitalismo industrial' con una 'globalización civilizadora'.

La noción de Thomas Berry (1999: 11) de La Gran Obra —una transición "de la época en que los humanos eran una fuerza perturbadora en el planeta Tierra al período en que los seres humanos se hacen presentes al planeta enriqueciéndose mutuamente"- , ha sido influyente en los DsT. Berry llama a la nueva era Ecozoica ${ }^{16}$. Para Berry, "la raíz más profunda de la actual devastación se encuentra en el modo de conciencia que ha establecido una discontinuidad radical entre los seres humanos y otros modos de ser y la concesión de todos los derechos a los seres humanos" (Íbid: 4). La radical discontinuidad entre los ámbitos humanos y no humanos es la base de muchas de las críticas. Junto con la idea de un yo separado (el 'individuo' de la teoría liberal, separado de la comunidad), esta discontinuidad se ve como el rasgo más fundamental de la ontología moderna. La superación de estas dos divisiones se plantea como fundamental para la sanación de la sociedad y el planeta desde las visiones seculares y religiosas por igual - ya sea a través de las nociones de la interconectividad y la interdependencia de la ecología, la idea de inter-existencia y co-emergencia de todos los seres del budismo, o los marcos basados en la auto-organización y la complejidad para los cuales lo que importa es la comprensión de los sistemas de relaciones co-emergentes. A las divisiones mencionadas anteriormente se agrega una tercera, entre los ámbitos humano y espiritual, o entre fe y razón, como se explica, de forma diciente, por parte de algunos científicos de sistemas y de la complejidad (por ejemplo, Laszlo, 2008; Kauffman, 2008). El enfatizar en la concepción de la Tierra como un sistema vivo donde todos los seres están profundamente interconectados, Macy (2007; Macy y Brown, 1998) habla de una revolución cognitiva y espiritual que implica la desaparición del yo moderno y su sustitución por un yo ecológico, no dualista, que se vuelve a conectar con todos los seres y recupera el sentido del tiempo evolutivo, borrado por el tiempo lineal de la modernidad capitalista; sólo de esta manera podremos aprender de nuevo a estar "en asociación con los seres del futuro" (Macy, 2007: 191), "sanar a nuestra cultura fragmentada" (Goodwin, 2007), y avanzar por los caminos de la transición.

Muchos de los DsT están sintonizados con la necesidad de desplazarse hacia economías post-carbono o post-combustibles fósiles. Vandana Shiva ha abogado por esto con una fuerza y perspicacia especial (véase especialmente 2005, 2008). Para Shiva, la clave de la transición 'del petróleo al suelo' (from oil to soil) — de un paradigma mecánico-industrial centrado en los mercados globalizados a uno centrado en la gente y el planeta, que ella llama democracia de la tierra - se encuentra en las estrategias de re-localización, es decir, la construcción de sistemas descentralizados de energía y producción de alimentos orgánicos basados en la biovidersidad y apoyados en formas de democracia directa, el conocimiento basado-en-lugar, las economías locales, y la preservación de los suelos y la integridad ecológica. Los DsT de este tipo muestran una aguda conciencia de los derechos de las comunidades

${ }^{16}$ Ver Greene (2003) y el trabajo del Centro de Estudios Ecozoicos en Chapel Hill, dirigido por Herman Greene http://www.ecozoicstudies.org/. 
a sus territorios y recursos, de los patrones tremendamente desiguales del consumo mundial, el impacto ambiental y las estructuras de explotación mantenidas por el capitalismo, y de la consiguiente necesidad de justicia social y ambiental. Esta es la razón de su insistencia en que "el imperativo que cambiemos nuestra manera de vivir" si queremos "ir más allá del petróleo" esté acoplado con la visión de la "necesidad de reinventar la sociedad, la tecnología y la economía" (Shiva, 2008: 1). En otras palabras, las críticas al capitalismo, el cambio cultural (a veces incluyendo la espiritualidad), y la ecología son sistemáticamente conectadas unas con otras en el diagnóstico de los problemas y posibles caminos a seguir (ver también, por ejemplo, Sachs y Santarius, 2007; Korten, 2006; Santos, 2007; Hathaway y Boff, 2009; Mooney et al., 2006; Shafer, 2008). La propuesta de la 'ecología de la transformación' (Hathaway y Boff, 2009) se considera como la vía para contrarrestar los estragos del capitalismo global y para la construcción de comunidades sustentables. Para Boff y Hathaway, los principales componentes de la estrategia son la justicia ecológica, la diversidad biológica y cultural, el biorregionalismo, el arraigo al lugar, la autonomía y la transparencia, la democracia participativa y la auto-organización cooperativa. Esta ecología supone una 'cosmología de la liberación' que está en sintonía con un tipo de espiritualidad adecuada a una era Ecozoica.

Una de las propuestas más concretas para una transición hacia una sociedad postcombustible fósil que responda adecuadamente a la crisis del petróleo y el cambio climático es el enfoque de la transición diseñado para poblados y comunidades con el objetivo de que creen sus propios discursos, escenarios y prácticas de transición: lo que se refiere como 'iniciativa de transiciones locales', ITL (transition town initiative; ver Hopkins, 2008; Chamberlin, 2009). Esta convincente visión comprende tanto el esbozo de un escenario post-petróleo a largo plazo y una guía para los poblados y comunidades a avanzar en un marco temporal de la transición. Una vez más, la re-localización de alimentos, energía y de la toma de decisiones son elementos cruciales de las ITL. La ITL también contempla la revitalización de las comunidades para que sean más localizadas y autosuficientes, con menos infraestructuras de energía ('descenso energético' o 'bajón de electricidad'), y, muy importante, las herramientas y procesos para la reconstrucción de la resilencia de los ecosistemas y las comunidades erosionada por siglos de sistemas económicos y políticos deslocalizados, dirigidos por expertos. La resilencia es en realidad el enfoque alternativo de la transición a las nociones convencionales de sostenibilidad; este enfoque requiere 'sembrar' las comunidades con diversidad, el aumento de la confianza social y ecológica en la auto-organización, el fortalecimiento de la capacidad de producir localmente lo que se puede producir localmente, y así sucesivamente. Tal como está planteada, sin embargo, la ITL, se encuentra más cerca al desarrollo alternativo que a las alternativas al desarrollo. Hay, pues, un puente importante que necesita ser construido entre la visión de la ITL y el postdesarrollo ${ }^{17}$.

${ }^{17}$ El enfoque de la transición es un concepto extraordinario y un conjunto de herramientas. Iniciado en la ciudad de Totnes, Devon, Reino Unido (también el hogar del Schumacher College), se ha extendido rápidamente. Más de cien comunidades en todo el mundo han elaborado 
En conjunto, se puede decir que estos trabajos imaginan una ecología de la transición, la cual puede ser considerada como un subcampo del campo más amplio de los estudios de la transición con el cual comenzó esta sección. Esta ecología de la transición plantea una profunda transformación cultural, económica, científica y política de las instituciones y prácticas dominantes - una tarea difícil por ciertoAl enfatizar la re-localización y la reconstrucción de las comunidades locales, va directamente en contra de la mayoría de los discursos y fuerzas de la globalización, apuesta al hecho de que lo 'pequeño' no sólo es posible sino tal vez inevitable (por ejemplo, Hopkins, 2008: 68-77; Estill, 2008). Al hacer visibles los dañinos efectos de las instituciones culturales del individuo y el mercado, dirigen nuestra atención a la necesidad de reconstruir la identidad y la economía, muchas veces en conjunto con las comunidades en las que los regímenes de la persona y el mercado todavía no se han consolidado completamente en la vida socio-natural. Abogan por una economía diversa que tiene un fuerte fundamento en las comunidades, aunque, por supuesto, no está circunscrita a lo local (Gibson-Graham, 2006). El foco de muchos DsT sobre la espiritualidad es un recordatorio de la exclusión sistemática de este importante sector en nuestras academias seculares. Al enfatizar la continuidad entre naturaleza y cultura, en fin, los DsT resaltan uno de los imperativos fundamentales de nuestro tiempo: la necesidad de volver a conectarnos entre sí y con el mundo no humano. Esta última es también una llamada para el posicionamiento del pluriverso, como veremos en la siguiente sección. ${ }^{18}$

\section{América Latina: ¿hacia un pluriverso? ${ }^{19}$}

Algunos movimientos y debates intelectuales de América Latina intuyen medidas posibles para alejarse del 'modelo civilizatorio' de la modernización y el desarrollo globalizado. Reunión tras reunión de pueblos indígenas, afrodescendientes, mujeres y campesinos, la crisis del modelo civilizatorio occidental es invocada como la causa más importante de la actual crisis global de energía/clima y pobreza. Un cambio hacia un nuevo paradigma cultural y económico es reconocido tanto como

planes de la transición inspirados en el Manual. La cartilla para las iniciativas de la transición es detallada y viable. Véase también el sitio web relacionado, http://transitionculture.org/.

${ }^{18}$ No voy a discutir aquí con más detalle lo que podríamos llamar 'la política de la transición', la cuals quedan implícitas en muchos DsT. Esta política puede ser fructíferamente teorizada desde la izquierda y enfoques académicos (por ejemplo, los imaginarios autonomistas anti-capitalistas, las politicas anti-capitalistas deleuzeanas/guattarianas, análisis foucaultianos y feministas posthumanistas y biopolíticos, la autonomía de América Latina, la geografía crítica, etc.), pero necesitaran enfrentar los desafíos epistémicos y ontológicos de los discursos de la transición no eurocéntrica y biocéntrica. En mi opinión, la sociología de las ausencias y de las emergencias de Boaventura de Sousa Santos (2007) constituye el marco general más útil para pensar la política de la transición/traducción.

${ }^{19}$ Para un exhaustivo abordaje de las transformaciones de América Latina durante la última década, incluyendo el argumento aquí realizado, y una serie completa de referencias, véase Escobar (2010a). 
necesario y como activamente en construcción ${ }^{20}$. Si bien el énfasis en una transición a nivel de todo el modelo de la sociedad es más fuerte entre algunos movimientos indígenas, también se encuentra, por ejemplo, en redes agroecológicas para las cuales solo un cambio hacia los sistemas agroecológicos de producción de alimentos localizados nos puede sacar de la crisis climática y alimentaria. Las propuestas agroecológicas resuenan con Shiva, y se les hacen eco parcialmente en la red global Vía Campesina, centrada en la soberanía alimentaria sobre la agricultura de base campesina. El significado de la transición y el postdesarrollo se puede vislumbrar con claridad en los debates más recientes sobre la definición del desarrollo y los derechos de la naturaleza que tienen lugar en países como Ecuador y Bolivia; y en una nueva ola de movimientos y luchas en estos países y en otras partes del continente que pueden ser interpretadas en términos de dos procesos interrelacionados, a saber, la activación de las ontologías relacionales y una redefinición de la autonomía política. Si bien estas tendencias son contradictorias y debatidas profundamente, apuntan hacia la importancia del postdesarrollo y hacen tangible la noción de órdenes sociales postliberales.

Las constituciones de Ecuador y Bolivia, sancionadas en 2008, han ganado una bien merecida atención internacional debido a sus tratamientos pioneros del desarrollo y, en el caso ecuatoriano, de los derechos de la naturaleza. Cabe destacar que estas constituciones son el resultado de complejas luchas sociales, culturales y políticas que se agudizaron en la década pasada. Las constituciones introdujeron una nueva noción de desarrollo centrada en el concepto de sumak kawsay (en quechua), suma qamaña (en aymara) o buen vivir (en español). Como Alberto Acosta, uno de los arquitectos más destacados de la constitución ecuatoriana, plantea el sumak kawsay supone una ruptura conceptual con las concepciones de desarrollo de las últimas seis décadas. Más que una declaración constitucional, "el Buen Vivir constituye una oportunidad para construir colectivamente un nuevo régimen de desarrollo" (2009: 6). Aunque un número de fuentes se citan como la base de esta concepción -incluyendo análisis críticos del desarrollo y del postdesarrollo, así como perspectivas feministas, ecologistas, y enfoques de desarrollo humano- la mayor proporción del crédito la tienen las organizaciones indígenas. Para Catherine Walsh (2009: 5), "la visión integral y la condición básica del Buen Vivir que han sido la base de las cosmovisiones, filosofías de vida y las prácticas de los pueblos del Abya Yala y los descendientes de la diáspora africana desde hace siglos, son ahora re-aprehendidos como guías para la refundación del Estado y la sociedad boliviana y ecuatoriana". En efecto, se puede decir que el sumak kawsay y suma qamaña nacen "de la periferia social de la periferia global", como lo ha planteado el crítico del desarrollo español José María Tortosa (citado en Acosta, 2010). Para el sociólogo peruano Aníbal Quijano (2010), el Buen Vivir constituye un nuevo horizonte de sentido histórico,

${ }^{20}$ Véase la edición N ${ }^{\circ} 453$ de América Latina en Movimiento (marzo de 2010) dedicada a las "Alternativas civilizatorias", http://alainet.org/publica/453.phtml. Un foro acerca de "Perspectivas sobre la 'Crisis de la Civilización' en el enfoque de los movimientos" se celebró en el Foro Social Mundial en Dakar (6 a 11 febrero, 2011), coordinado por Roberto Espinoza, Janet Conway, Jai Sen y Carlos Torres. Se contó con participantes de varios continentes. 
surgido de la larga historia de resistencia indígena contra el sistema mundo moderno/colonial eurocéntrico.

Muy sucintamente, y siguiendo a Acosta y a Gudynas ${ }^{21}$, el Buen Vivir (BV) surgió de varias décadas de luchas indígenas, las cuales se articularon con agendas múltiples de cambios sociales de los campesinos, afrodescendientes, ambientalistas, estudiantes, mujeres y jóvenes. Cristalizado en 99 artículos de la Constitución (de un total de 444), el BV "se presenta como una oportunidad para la construcción colectiva de una nueva forma de vida" (Acosta, 2010: 7). Antes que una intervención aislada, el BV debe considerarse en el contexto de toda una gama de innovaciones constitucionales pioneras, incluyendo el replanteamiento del Estado en términos de plurinacionalidad, de la sociedad en términos de interculturalidad, una noción amplia e integral de los derechos (incluidos los derechos a la naturaleza, abajo), y un modelo de desarrollo reformado, cuyo objetivo es precisamente la realización del BV. Todas estas innovaciones, además, deben ser consideradas como multiculturales, multi-epistémicas, y en términos de procesos de construcción política profundamente negociados y a menudo contradictorios. Es claro, sin embargo, que el BV constituye un desafío a nociones de desarrollo de larga data.

Las ontologías o 'cosmovisiones' indígenas no implican una noción lineal del desarrollo, ni un estado de 'subdesarrollo' que hay que superar, ni están basadas en la 'escasez' o la primacía de los bienes materiales. Haciendo eco de estos principios, el BV pretende introducir una filosofía de vida diferente en la visión de sociedad. Esto hace posible una ética del desarrollo que subordina los objetivos económicos a criterios ecológicos, a la dignidad humana y a la justicia social. El desarrollo como Buen Vivir busca articular la economía, el medio ambiente, la sociedad y la cultura en nuevas formas, llamando a las economías sociales y solidarias mixtas; introduce temas de justicia social e intergeneracional en los espacios de los principios del desarrollo; reconoce las diferencias culturales y de género, posicionando la interculturalidad como principio rector; y permite los nuevos énfasis político-económicos, tales como la soberanía alimentaria, el control de los recursos naturales y un derecho humano al agua. Sería un error, sin embargo, considerar el BV como un proyecto cultural-político puramente andino, un punto que Acosta (2010) afirma rotundamente. Como ya se mencionó, el BV también está influenciado por las corrientes críticas del pensamiento occidental, y su objetivo es influir en los debates globales. Dicho esto, existe un amplio reconocimiento de que los conocimientos indígenas y afro han sido sometidos a procesos de marginación de larga data, o lo que en algunas de las perspectivas actuales de América Latina se conoce como 'colonialidad'. El BV, de esta manera, busca revertir la colonialidad del poder, del conocimiento y del ser que han caracterizado al sistema mundo moderno/colonial desde la conquista (Quijano, 2010). En algunos debates en los países andinos, esto se conoce como 'descolonización epistémica'.

${ }^{21}$ Para la presentación y análisis de las nociones de Buen Vivir, derechos de la naturaleza y la plurinacionalidad, ver los valiosos pequeños volúmenes de Acosta y Martínez (2009a, 2009b, 2009c), Acosta (2010), y Gudynas (2009a, 2009b). 
Muchos de los argumentos acerca del BV también se pueden hacer con respecto a otra idea principal de la Constitución, la de los derechos de la naturaleza; de hecho, los dos aspectos están estrechamente relacionados entre sí. Para el ecologista social uruguayo Eduardo Gudynas (2009a, 2009b), los derechos de la naturaleza o la Pachamama, reconocidos en la nueva Constitución del Ecuador, representan un 'giro biocentrico' sin precedentes, lejos del antropocentrismo de la modernidad. Para Gudynas, este movimiento resuena tanto con las cosmovisiones de los grupos étnicos como con los principios de la ecología. Dotar a la naturaleza de los derechos significa pasar de una concepción de la naturaleza como objeto para ser explotado a una en la que la naturaleza es vista como sujeto; de hecho, en esta concepción la idea de los derechos de la naturaleza está íntimamente relacionada con el derecho a existir de los seres humanos. Este aspecto de la Constitución busca contrarrestar un supuesto ontológico central del sistema capitalista moderno/colonial, que está en la base de la destrucción sistemática de la existencia biofísica, es decir, la separación entre los seres humanos y no humanos. También implica una noción ecológica expandida del yo que, a diferencia de la noción liberal, considera al yo profundamente interconectado con todos los otros seres vivos y, en última instancia, con el planeta como un todo. Para Gudynas, esto equivale a una especie de 'meta-ciudadanía ecológica', una forma plural de la ciudadanía que involucra dimensiones culturales y ecológicas, y que requiere tanto de la justicia ambiental como de la justicia ecológica para la protección de las personas y la naturaleza, respectivamente ${ }^{22}$. De este modo, el giro biocéntrico en la Constitución representa un ejemplo concreto de la transformación civilizacional imaginada por los discursos de la transición discutidos anteriormente.

El reconocimiento de los derechos de la naturaleza está estrechamente relacionado con el último aspecto de las transformaciones de América Latina que quiero discutir, aunque sea muy brevemente; esto es la noción y la práctica de la relaciona$\operatorname{lidad}^{23}$. Hay una convergencia interesante entre ciertas narrativas filosóficas, biológicas y de los pueblos indígenas en la afirmación de que la vida implica la creación de la forma (la diferencia, la morfogénesis) a partir de la dinámica de la materia y la energía $\mathrm{a}^{24}$. En estas concepciones, el mundo es un pluriverso, en incesante movimiento, una red siempre cambiante de interrelaciones entre seres humanos y no humanos. Es importante señalar, sin embargo, que el pluriverso da lugar a coherencias y cristaliza en prácticas y estructuras a través de procesos que tienen mucho que ver con los significados y el poder; de esta manera esto se puede ver en términos de una multiplicidad de mundos. Con la ontología moderna, como ya se ha sugerido, ciertas construcciones y prácticas han llegado a ser prominentes. Estos supuestos incluyen la primacía ontológica de los seres humanos sobre los no-humanos (la

${ }^{22}$ En ambos, Gudynas y Macy, esta noción transformada del yo se basa en el enfoque de ecología profunda de Arne Naess y su visión pionera del yo ecológico.

${ }^{23}$ Ver Escobar (2010b) para una discusión completa de la literatura sobre la relacionalidad en geografía, antropología y ecología.

${ }^{24}$ En algunos relatos indígenas, la creación de la forma es vista como el paso de la 'indistinción’ a la ‘distinción’ (véase, por ejemplo, Blaser 2010 para el caso de los Yshiro de Paraguay). 
separación de la naturaleza y la cultura) y de algunos seres humanos sobre otros (la brecha colonial entre el Occidente/ moderno y el resto/ no moderno); la separación del individuo autónomo de la comunidad; la creencia en el conocimiento objetivo, la razón y la ciencia como los únicos modos de conocimiento válido; y la construcción cultural de la 'economía' como un reino independiente de la vida social, con el 'mercado' como una entidad auto-regulada. Los mundos y saberes construidos sobre la base de estos compromisos ontológicos devinieron en 'un universo'. Este universo ha adquirido cierta coherencia en formas socio-naturales como el capitalismo, el Estado, el individuo, la agricultura industrial, proyectos de macro-desarrollo, y así sucesivamente ${ }^{25}$.

Es precisamente este conjunto de supuestos que las discusiones sobre el BV y los derechos de la naturaleza perturban. A pesar de que no se puede discutir este punto aquí en detalle, perturbar las construcciones modernas apunta a la existencia de órdenes sociales no-liberales o post-liberales ${ }^{26}$; estos son mundos que van más allá de las nociones liberales fundacionales del individuo, la propiedad privada y la democracia representativa. Dicho en términos antropológicos y filosóficos, estos mundos no-liberales están basados-en-lugar y pueden ser caracterizados como instancias de cosmovisiones u ontologías relacionales. Ontologías relacionales son aquellas que evitan la división entre naturaleza y cultura, entre individuo y comunidad, y entre nosotros y ellos que son fundamentales para la ontología moderna. Esto quiere decir que algunas de las luchas en Ecuador y en Bolivia (y en otras partes del continente, incluyendo las luchas por la autonomía en Chiapas y Oaxaca, así como las luchas indígenas y afro y otras luchas campesinas en Colombia, Perú, Guatemala, y otros países) pueden leerse como luchas ontológicas; tienen el potencial de desnaturalizar los dualismos hegemónicos en los que se funda el orden liberal (Blaser, 2010; de la Cadena 2010; Escobar 2010a ; Povinelli 2001). La tendencia universal y homolingüe de la modernidad dicta que se debe tratar de dominar esos mundos diferentes, es decir, borrar el pluriverso. El visibilizar el pluriverso centrándose en los conflictos ontológicos - es decir, los conflictos que surgen del encuentro desigual entre dos mundos, como en tantos conflictos relacionados con la explotación de los recursos hoy en día- se puede decir que constituye un campo de estudio al que se refiere Blaser (2010) como ontología política ${ }^{27}$.

${ }^{25}$ Esta es una elaboración muy incompleta de lo que es un debate complejo que involucra cuatro posiciones sobre la modernidad: a) la modernidad como un proceso universal de origen europeo (discursos intra-euro/estadounidenses), b) las modernidades alternativas (variantes locales específicas de la misma modernidad universal), c) las modernidades múltiples, es decir, la modernidad como multiplicidad sin un origen o matriz cultural únicos (Grossberg, 2010), d) la modernidad/colonialidad, que señala la inextricable imbricación de la modernidad con la clasificación colonial de los pueblos en jerarquías, y la posibilidad de 'alternativas a la modernidad' o la transmodernidad. Ver Escobar (2008a), capítulo 4 para un tratamiento más completo.

${ }^{26}$ Ver Escobar (2010a) para una discusión completa, con especial referencia a Bolivia y, en particular, al trabajo de intelectuales aymara y otros latinoamericanos sobre el tema.

${ }^{27}$ Los conflictos ontológicos involucrados en las economías neo-extractivistas son objeto de un proyecto de investigación colaborativa adelantado por Mario Blaser, Marisol de la Ca- 
La aparición de las ontologías relacionales desafía el fundamento epistémico de la política moderna. Que la identificación de la naturaleza con la Pachamama, y el hecho de que está dotada de 'derechos' va más allá de un ambientalismo políticamente correcto, dado que la Pachamama no puede encajar fácilmente en la estructura filosófica de la constitución moderna, en la cual la naturaleza es vista como un objeto inerte para que los seres humanos se la apropien. Su inclusión en la Constitución contribuye así a romper el espacio político y epistémico moderno ya que ocurre por fuera de dicho espacio (de la Cadena, 2010). Algo similar puede decirse de la noción del Buen Vivir. Ambos conceptos se basan en supuestos ontológicos en los que todos los seres existen siempre en relación, y no como 'objetos' o individuos. Lo que está en juego en muchas movilizaciones político-culturales en América Latina en la actualidad, de esta manera, es la activación política de las ontologías relacionales; estas movilizaciones se refieren así a una manera diferente de imaginar la vida, a un otro modo de existencia (Quijano, 2010). Apuntan hacia el pluriverso; en la conocida fórmula de los zapatistas, el pluriverso puede ser descrito como "un mundo donde quepan muchos mundos". Tal vez de manera más abstracta, el pluriverso indica las luchas por lograr 'mundos y conocimientos de otro modo' - es decir, mundos y saberes construidos sobre la base de los diferentes compromisos ontológicos, configuraciones epistémicas y prácticas del ser, saber y hacer-

Las nociones de prácticas no-liberales y no-capitalistas están siendo activamente desarrolladas en América Latina, particularmente en relación con las formas urbanas y rurales de la movilización popular en Oaxaca, Chiapas, Ecuador, Bolivia y el suroccidente de Colombia ${ }^{28}$. No se trata simplemente de nociones teóricas, sino el resultado de los enraizados análisis políticos, particularmente en términos del desarrollo de las formas de autonomía que incluyen formas no estatales de poder derivadas de las prácticas comunitales culturales, económicas y políticas (Esteva, 1997, 2005, 2006; Patzi, 2004; Mamani, 2005, 2006; Zibechi, 2006; Gutiérrez, 2008). En algunos casos, como en las comunidades zapatistas de Chiapas o las comunidades indígenas de Oaxaca, las formas autónomas de gobierno comunal contemporáneas se consideran enraizadas en varios siglos de resistencia indígena. En otros casos, como las comunidades aymaras urbanas de El Alto, Bolivia, lo que ocurre es una creativa re-constitución de la lógica comunitaria sobre la base de nuevas formas de territorialidad. Sin embargo, la mayoría de los casos de organización autónoma implican ciertas prácticas clave, tales como las asambleas comunales, la rotación de las obligaciones y formas de poder horizontal y disperso. En las formas comunales, el poder no funciona sobre la base de la representación liberal, sino que se funda en formas alternativas de organización social. La autonomía es, pues, un proceso tanto cultural como político. Se trata de formas autónomas de existencia y organización política autónoma y de toma de decisiones. Como dicen los zapatistas, el objetivo de la autonomía no es tanto tomar el poder y cambiar el mundo sino crear uno nuevo.

dena y este autor. El objetivo general del proyecto es el de la teorización del pluriverso como un espacio de las prácticas ontológicas-políticas.

${ }^{28}$ Algunos de los textos principales incluyen Esteva (1997, 2005, 2006); Gutiérrez (2008); Mamani (2005, 2006); Zibechi (2006) y Patzi (2004). 
La autonomía puede ser descrita en términos de democracia radical, autodeterminación cultural y autogobierno.

Lo que surge de esta interpretación es una cuestión fundamental, la de "ser capaz de estabilizar en el tiempo un modo de regulación fuera de, contra y más allá del orden social impuesto por la producción capitalista y el Estado liberal" (Gutiérrez, 2008: 46). Esta propuesta implica tres puntos básicos: la descentralización y el desplazamiento constante de la economía capitalista con la consiguiente expansión de diversas formas de economía, incluyendo las formas comunitarias y no capitalistas; la descentralización de la democracia representativa y el establecimiento en su lugar de formas de democracia directa, autónoma y comunales; y el establecimiento de mecanismos de pluralismo epistémico y cultural (interculturalidad), entre ontologías y mundos culturales diferentes. Desde una perspectiva postestructuralista, es posible hablar de la aparición de formas post-liberales y postcapitalistas de organización social. Es importante dejar en claro una vez más lo que significa 'post'. El postdesarrollo señaló la posibilidad de visualizar una época donde el desarrollo dejaba de ser un principio central de organización de la vida social; más aún, visualizaba tal desplazamiento como ocurriendo en el presente. Lo mismo es cierto para el postliberalismo, como un espacio/tiempo en construcción, cuando la vida social ya no está completamente determinada por las construcciones de la economía, el individuo, la racionalidad instrumental, la propiedad privada, y así sucesivamente. 'Postcapitalista' significa igualmente ver la economía como formada por una diversidad de prácticas capitalistas, capitalistas alternativas y no capitalistas (Gibson-Graham, 2006). El post, de manera sucinta, significa un descentramiento del capitalismo en la definición de la economía, del liberalismo en la definición de la sociedad y de las formas estatales de poder como la matriz definidora de organización social. Esto no quiere decir que las formas del capitalismo, el liberalismo y el Estado dejarán de existir, sino que su centralidad discursiva y social se han desplazado en alguna medida, por lo que el rango de las actuales experiencias sociales que son consideradas como alternativas válidas y creíbles a lo que existe se amplía de manera significativa (Santos, 2007).

Como enfatizan los proponentes del BV y de los derechos de la naturaleza, estas nociones deben considerarse como procesos en construcción en lugar de conceptos acabados. Esto es aun más valido al considerar que la mayor parte de las políticas de los gobiernos progresistas en la actualidad minan las propias condiciones para su realización. A pesar de su ruptura con muchos de los principales postulados del modelo económico neoliberal, la mayoría de estos gobiernos mantienen estrategias de desarrollo basadas en la exportación de recursos naturales, tales como materias primas agrícolas y minerales, incluyendo petróleo y gas, pero también nuevas rúbricas como la soja en Argentina y Brasil. La principal diferencia en estas políticas de gobierno reside en que los ingresos se apropian de manera diferente, con especial énfasis en la reducción de la pobreza a través de políticas redistributivas. Pero la orientación neo-extractivista del modelo plantea un enorme desafío y es la principal fuente de tensión entre Estados y sectores de la sociedad civil (Gudynas, 2010a). Este modelo afecta enormemente las posibilidades de la aplicación de los derechos 
a la naturaleza, en tanto el neo-extractivismo de los gobiernos progresistas no sólo toleran sino que coexiste fácilmente con la destrucción del ambiente (Gudynas, 2010b). También está claro, sin embargo, que los conceptos de derechos de la naturaleza y Buen Vivir han logrado colocar la cuestión del desarrollo nuevamente en la agenda con particular agudeza. Esto implica, a su vez, la apertura de la cuestión de la transición a una sociedad post-extractivista. En Ecuador y Bolivia en particular, el post-estractivismo y el post-desarrollo reúnen en un debate crucial e intenso al Estado, las ONG, los movimientos sociales y los intelectuales. Existe la sensación de un impasse creado por la tensa convivencia de las políticas progresistas pero aún economicistas y desarrollistas a nivel del Estado, por un lado, y la capacidad de los movimientos para cuestionar tales políticas desde abajo por otro lado - un tipo de 'mezcla promiscua' de la hegemonía capitalista y los contrapoderes del movimiento, de exigencias radicales para el cambio y la reconstitución de la dominación-(Colectivo Situaciones, 2009). Cómo opera esta dinámica en cada país no puede ser decidido de antemano y será de importancia más allá de la región dada la intensificación del extractivismo en el mundo por el capitalismo colonial global —una recolonización global cada vez más cínica y destructiva, como lo sugieren las lecturas críticas de la película Avatar-.

Para volver una última vez a la pregunta con la que se inició este capítulo, ¿sigue siendo útil la noción de postdesarrollo para transmitir tanto el decentramiento del desarrollo y la reorientación de la práctica? Es cierto que el 'postdesarrollo' ha llegado a tener muy diversos, y a menudo dispares, significados. Esta es la razón por la que traté de caracterizarlo de nuevo con cuidado al principio de estas notas. También es importante reconocer la existencia de otras aéreas de investigación y de la vida social que podrían ser considerados relacionadas con, o como avanzando hacia, el postdesarrollo ${ }^{29}$. Al mismo tiempo, es posible identificar las áreas en las cuales el análisis del postdesarrollo continúa siendo de utilidad directa, incluyendo las siguientes: el surgimiento de nuevos espacios, como el Buen Vivir, para reconceptualizar la realidad social y, por lo tanto, para descentrar el desarrollo; los cambios en las condiciones de la producción del conocimiento sobre el desarrollo ('economía política de la verdad' del desarrollo), resultando en una pluralización de los conocimientos, incluidos los de los activistas de los movimientos sociales; y un cuestionamiento renovado de principios fundamentales de la modernidad eurocéntrica - desde el progreso lineal y el valor económico estándar hasta el individuo liberal y la naturaleza como inerte- fortaleciendo así los enfoques no antropocéntricos y no economicistas. El postdesarrollo sigue siendo útil en la articulación de las críticas de las tendencias existentes (por ejemplo, el neo-extractivismo), para descentrar los debates y orientar la investigación hacia posibilidades no-economicistas, y para

${ }^{29}$ En nuestra discusión sobre el estado actual de postdesarrollo (abril, 2010), Gudynas y yo hemos identificado varias áreas principales o corrientes relacionadas con el postdesarrollo. Entre ellas, además del BV y el biocentrismo, se encuentran los debates sobre la desmaterialización y el decrecimiento, las múltiples formas de valoración, la territorialidad y las nuevas formas de concebir la ruralidad, la decolonialidad, el cuidado y la espiritualidad, y las ontologías relacionales. Está claro que sólo me he referido a algunas de ellas en este prefacio. 
mantener vivo el imaginario del más allá del desarrollo y de las alternativas al desarrollo (por ejemplo, el post-extractivismo y las transiciones culturales y ecológicas). Por supuesto, es el caso de que muchos de estos aspectos críticos relativos a la globalización, la naturaleza y la economía han surgido en respuesta a otros procesos sociales, intelectuales y políticos, y no necesariamente en relación con el desarrollo per se. En este sentido, sería más apropiado sugerir que el postdesarrollo sigue siendo un concepto apto para volver a impulsar, y contribuir a articular, muchas de las preguntas cruciales del presente.

Más que un desarrollo alternativo, el Buen Vivir constituye una alternativa al desarrollo, y en esa medida se puede ver como un avance en "el camino hacia el postdesarrollo" (Acosta, 2010). En el mejor de los casos, se puede decir que el despliegue de conceptos y de las luchas en torno al Buen Vivir y los derechos de la naturaleza, surgiendo bajo la influencia toque de la autonomía, constituyen una teoría y práctica post-dualista: es decir, una práctica del inter-ser. Como tales, son elementos clave en los diseños para el pluriverso. Implican formas relacionales de ser, hacer y conocer. De esta manera, las tendencias revisadas en esta sección se sitúan de lleno dentro de los discursos de la transición. Esto permite una cierta radicalización de la discusión del postdesarrollo. Esta es una discusión en la que todas las voces críticas pueden contribuir, ya sea en el Sur o el Norte global.

\section{Conclusión. El fin de la globalización (tal como la conocíamos)}

En su libro, El fin del capitalismo (como lo conocíamos), las geógrafas feministas Gibson y Graham (1996) nos invitan a imaginar un momento cuando el dominio de la economía no sea tan aparentemente natural y completamente ocupado por el capitalismo. La tendencia del capitalismo a ocupar la economía, argumentan, es por lo menos en parte, un artefacto de los discursos y hábitos de pensamiento impulsados por las teorías académicas de la economía política en ámbitos como el desarrollo y los estudios de la globalización. En otras palabras, nuestras propias teorías dotan al capitalismo con tanta capacidad para dominar y 'penetrar' que se vuelve imposible para nosotros ver el espectro de diferencia económica que habita realmente en la vida social. Al liberar la economía del capitalocentrismo, el objetivo es volver a teorizarlo como diverso, y convertir esa diversidad en un punto de encuentro para las luchas por las subjetividades no-capitalistas y construcciones alternativas del mundo.

Me parece que algo similar ha ocurrido con los discursos de la globalización de todo tipo. En estos discursos, ya sean convencionales o de izquierda, un supuesto 'espacio global' es visto como natural y totalmente ocupado por formas de vida socio-naturales, que son una extensión de la modernidad al estilo occidental. No importa cuán cualificada, la globalización en estos discursos siempre equivale a una profundización y a una universalización de la modernidad capitalista. Hay algo terriblemente erróneo con este imaginario, si vamos a tomar en serio los discursos de la transición, el concepto de Buen Vivir y los derechos de la naturaleza, y mucho más si queremos enfrentar la cada vez peor crisis ecológica. Para parafrasear una vez más, escarbe un discurso de la globalización y encontrará el homo oeconomicus por 
todos lados; supuestos 'individuos' insistiendo en convertirse en clones en miniatura del capitalismo (a través de, por ejemplo, la microfinanciación, el desarrollo rural modernizante); los supuestos de la racionalidad lineal como el modo automático de pensar de quienes quieran "triunfar en un "mundo competitivo"; una visión de la naturaleza como recurso a extraer a cualquier precio; o incluso de grupos y movimientos que luchan desde dentro para recuperar el proyecto moderno con propósitos emancipadores. Como lo planteé en 1995, haciendo eco de la obra de la socióloga feminista canadiense Dorothy Smith (véase el Capítulo 4 del libro del que este prefacio es parte), estos discursos reflejan una visión del mundo como es concebido por quienes lo gobiernan - un mundo desde arriba - Estos discursos despliegan eficientes aparatos de poder que organizan las percepciones y experiencias de la gente.

Cabe reiterar que este punto de vista de la globalización como universal, totalmente economizada, deslocalizada, multi-cultural (aunque con las culturas modernas como el modelo por excelencia), donde 'individuos' (ricos) están dotados de 'derechos' y las naciones tienen que aceptar los dictados de la misma racionalidad global a riesgo de convertirse en 'Estados fallidos', es cada vez más posible gracias al inmenso poder de las corporaciones y es mantenido dentro de niveles manejables de des/orden por la fuerza militar. La cara oculta de la globalización, de esta manera, no es otra que la colonialidad global. Desde sus mismas condiciones globales están surgiendo, sin embargo, las respuestas y las formas de creatividad y resistencia que hacen cada vez más visible la pobreza, lo pernicioso y destructivo de este imaginario.

Como plantea Blaser (2010), el momento actual puede ser considerado como uno de intensa lucha entre dos visiones de la globalidad: la globalidad definida como la modernidad universalizada, o la globalidad como un pluriverso - 0 , como lo enuncié antes, entre el mundo como universo y el mundo como pluriverso- ${ }^{30}$. Antes que en términos de la globalización, esta última posibilidad sería más apropiada describirla como un proceso de planetarización articulado en torno a una visión de la Tierra como un todo viviente que está siempre emergiendo de un ensamblaje de elementos y relaciones biofísicas, humanas y espirituales que hacen el pluriverso, desde la biosfera y la mecanosfera a la noosfera. Muchas de las funciones previstas en los discursos de la transición - desde las estrategias de re-localización hasta el surgimiento de una civilización ecológica-, encontrarán un espacio más acogedor en este concepto. Tenemos que dejar de apabullar a la Tierra con los dualismos de los siglos pasados, y reconocer la interrelación, apertura y pluralidad radicales que la habitan. Para lograr este objetivo, tenemos que empezar a pensar en la práctica humana en términos de diseño ontológico, o diseño de mundos y conocimientos de otro modo. Uno de los principios del diseño ontológico es el de construir en la diversidad ya existente, o sembrar diseños con la diversidad, lo que es el principio

${ }^{30}$ Se puede argumentar que 'el mundo como pluriverso' es un oxímoron. Estoy tratando de mantener una tensión entre las epistemologías monistas o monismo metafísico, como los del científico de la computación Brian Cantwell Smith (1996) y los antropólogos ecológicos como Alf Hornborg (1996), y las posiciones de quienes postulan la coexistencia de mundos diferentes $-\mathrm{y}$ al menos en parte inconmensurables-. 
para el pluriverso. El diseño ya no implicaría la domesticación del mundo para (algunos) propósitos humanos, sino, para retomar las palabras de Berry (1999: 11), la construcción de mundos en los que los seres humanos y la Tierra pueden co-existir enriqueciéndose mutuamente. Más políticamente, "de esta manera la defensa de la vida humana, y las condiciones de vida en el planeta, puede convertirse en el nuevo horizonte de sentido de las luchas de resistencia de la mayoría de la población mundial" (Quijano, 2010: 7).

Yendo mucho más allá de la crítica, un campo naciente de los estudios pluriversales debería - y ya lo hace, como he tratado de demostrar en las dos últimas secciones - descubrir las formas adoptadas por los múltiples mundos que componen el pluriverso, sin tratar de reducirlos a las manifestaciones de principios conocidos. Los estudios pluriversales se centrarían en aquellos procesos que ya no pueden ser fácilmente acomodados en la tabla epistémica de las ciencias sociales modernas. Esta es la razón por la cual los estudios pluriversales no pueden ser definidos en oposición a los estudios de la globalización, ni como su complemento, sino que requieren ser esbozados como un proyecto intelectual y político completamente diferente. No existe una noción única del mundo, el ser humano, la civilización, el futuro, o incluso lo natural que pueda ocupar totalmente el espacio de los estudios pluriversales. Incluso si en parte basándose en la tradición crítica de las ciencias naturales, humanas y sociales modernas, los estudios pluriversales viajarán su propio camino a medida que descubran mundos y conocimientos que las ciencias han desconocido o sólo oblicuamente considerado. Para que los estudios críticos del desarrollo estén en sintonía con este proyecto, se requeriría de una transformación mucho más significativa que la permitida por el postdesarrollo.

Traducción: Eduardo RESTREPO

\section{Referencias bibliográficas}

ACOSTA, Alberto

2010 El Buen Vivir en el camino del post-desarrollo. Una lectura desde la Constitución de Montecristi. Quito: Fundación Friedrich Eber, FES-ILDIS

2009 'El Buen Vivir, una oportunidad por Construir'. Ecuador Debate, no. 75, pp. 33-48.

ACOSTA, Alberto y MARTÍNEZ, Esperanza (Eds.)

2009a El buen vivir. Una via para el desarrollo. Quito: Abya-Yala.

2009b Plurinacionalidad. Democracia en la diversidad. Quito: Abya-Yala.

2009 Derechos de la naturaleza. El futuro es ahora. Quito: Abya-Yala.

ANDOLINA, Robert; LAURIE, Nina; RADCLIFFE, Sarah (Eds.)

2009 Indigenous Development in the Andes. Durham: Duke University Press.

ARCE, Alberto y LONG, Norman (Eds.)

2000 Anthropology, Development, and Modernities. Londres: Routledge. 
ASHER, Kiran

2009 Black and Green: Afro-Colombians, Development, and Nature in the Pacific Lowlands. Durham: Duke University Press.

\section{BEBBINGTON, Anthony}

2004 NGOs and Uneven Development: Geographies of Development Intervention. Progress in Human Geography 28(6): 725-745.

BELLAMY FOSTER, John y MAGDOFF, Fred

2008 Financial Implosion and Stagnation: Back to the real Economy. Monthly Review 60(7): 1-29.

BERRY, Thomas

1999 The Great Work: Our Way into the Future. New York: Bell Tower.

BHAVNANI, Kum-Kum; FORAN, John; KURIAN, Priya (Eds.)

2003 Feminist Futures. Re-imagining Women, Culture, and Development. Londres: Zed Books.

BIDASECA, Karina

2010 Perturbando el Texto Colonial: Los Estudios (Pos)coloniales en América Latina. Buenos Aires: Editorial SB.

BIERSACK, Aletta y GREENBERG, James (Eds.)

2006 Re-imagining Political Ecology. Durham: Duke University Press.

BLASER, Mario

2004 "Life Projects. Indigenous People's Agency and Development". En: BLASER, Mario; FEIT, Harvey; y McRAE, Glenn (Eds.), In the Way of Development. Indigenous Peoples, Life Projects, and Globalization, 28-42. Londres: ZED Books.

2010 Storytelling Globalization: From the Chaco and Beyond. Durham: Duke University Press.

BLASER, Mario; FEIT, Harvey; MCRAE Glenn (Eds.)

2004 In the Way of Development. Indigenous Peoples, Life Projects, and Globalization. Londres: ZED Books.

HATHAWAY, Mark y BOFF, Leonardo

2009 The Tao of Liberation. Exploring the Ecology of Transformation. Maryknoll, New York: Orbis Books.

CASAS-CORTÉS, Maribel; OSTERWEIL, Michal; POWELL, Dana

2006 Blurring Boundaries: Recognizing Knowledge-Practices in the Study of Social Movements. Anthropological Quarterly 81(1): 17-58

CASTELLS, Manuel

1996 The Rise of the Network Society. Oxford: Blackwell.

COLECTIVO SITUACIONES (Ed.)

2009 Conversaciones en el impasse. Buenos Aires: Tinta Limón. 
DAR, Sadhvi y COOKE, Bill (Eds.)

2008 The New Development Management. Londres: Zed Books.

DE LA CADENA, Marisol

2010 Indigenous Cosmopolitics in the Andes: Conceptual Reflections Beyond Politics. Cultural Anthropology 25(2): 334-370.

DE LA CADENA, Marisol y STARN, Orin (Eds.)

2007 Indigenous Experience Today. Oxford: Berg.

DE VRIES, Pieter

2007 Don't Compromise Your Desire for Development: A Lacanian/Deleuzian Rethinking of the Anti-Politics Machine. Third World Quarterly 28(1): 25-43.

2008 The Managerialization of Development, the Banalization of Its Promises, and the Disavowal of 'Critique' as a Modernist Ilusion. En: Sadhvi Dar y Bill Cooke (eds), The New Development Management, 150-176. Londres: Zed Books.

DESMERAIS, Annette

2007 La Via Campesina: Globalization and the Power of Peasants. Halifax. Fernhood Publishing.

ESCOBAR, Arturo

1992 Imagining a Postdevelopment Era? Critical Thought, Development, and Social Movements. Social Text 31/32: 20-56.

2000 Beyond the Search for a Paradigm? Post-development and Beyond. Development 43(4): 11-14.

2005 Economics and the Space of Modernity: Tales of Market, Production and Labor. Cultural Studies 19(2): 139-175.

2007 Post-development as Concept and Social Practice. En: Aram Ziai (Ed.), Exploring Post-development, 18-32. Londres: Zed Books.

2008a Territories of Difference: Place Movements Life Redes. Durham: Duke University Press.

2008b Development, Trans/modernities, and the Politics of Theory. Focaal 52: 127-135.

2010a Latin America at a Crossroads: Alternative Modernizations, Postliberalism, or Postdevelopment? Cultural Studies 24 (1): 1-65.

2010b Postconstructivist Political Ecologies. En: International Handbook of Environmental Sociology, Segunda edición, REDCLIFT, Michael y WOODGATE, Graham (Eds.), 91-105. Cheltenham, UK: Elgar.

ESTEVA, Gustavo

1997 The Meaning and Scope of the Struggle for Autonomy. Presentada en el Congreso de LASA, Guadalajara, México, abril 17-19.

2005 Celebration of Zapatismo. Humboldt Journal of Social Relations 29(1): 127-167.

2006 The 'Other Campaign' and the Left: Reclaiming an Alternative. Manuscrito inédito, Universidad de la Tierra, Oaxaca.

2009 What is Development? Manuscrito inédito, Universidad de la Tierra, Oaxaca.

ESTILL, Lyle

2008 Small is Possible. Life in a Local Economy. Gabriola Island, BC: New Society Publishers. 
FERGUSON, James

1990 The Anti-Politics Machine. Cambridge: Cambridge University Press.

FRENCH, Jan

2009 Legalizing Identities: Becoming Black or Indian in Brazil's Northeast. Durham: Duke University Press.

GIBSON-GRAHAM, J.K

2006 A Postcapitalist Politics. Minneapolis: University of Minnesota Press.

1996 The End of Capitalism (as we knew it). Oxford: Blackwell.

GOODWIN, Brian

2007 Nature's Due: Healing Our Fragmented Culture. Edimburgo: Floris Books.

GOULD, Jeremy

2005 "Timing, Scale and Style: Capacity as Governmentality in Tanzania". En: MOSSE, David y LEWIS, David (Eds.), The Aid Effect: Giving and Governing in International Development, 61-84. Londres: Pluto Press.

GOW, David

2008 Countering Development. Indigenous Modernity and the Moral Imagination. Durham: Duke University Press.

GREENE, Herman

2003 Process Thought for What? The Ecozoic Era, the Great Work, and the Importance of Process Thought. Chapel Hill. Manuscrito inédito.

GREENOUGH, Paul y LOWENHAUPT TSING, Anna (Eds.)

2003 Nature in the Global South: Environmental Projects in South and Southeast Asia. Durham: Duke University Press.

GROSSBERG, Lawrence

2010 Cultural Studies in the Future Tense. Durham: Duke University Press.

GUDYNAS, Eduardo

2009a El Mandato Ecológico: Derechos de la Naturaleza y Políticas Ambientales en la Nueva Constitución. Quito: Abya-Yala.

2009b La Ecología Política del Giro Biocéntrico en la Nueva Constitución de Ecuador, Revista Estudios Sociales 32: 34-47. Bogotá.

2010a Las Nuevas Intersecciones Entre Pobreza y Desarrollo: Tensiones y Contradicciones de la Sociedad Civil y los Gobiernos Progresistas. Surmanía (Universidad Nacional de Colombia, Bogotá) 4: 92-111.

2010b Si Eres Tan Progresista, Por Qué Destruyes la Naturaleza? Neoextractivismo, Izquierda y Alternativas. Ecuador Debate (Quito) 79: 61-81.

GUTIÉRREZ A., Raquel

2008 Los ritmos del Pachakuti. Movilización y levantamiento indígena-popular en Bolivia. Buenos Aires: Tinta Limón. 
HANH, Thich Nhat

2008 The World We Have: A Buddhist Approach to Peace and Ecology. Berkeley: Parallax Press.

HARCOURT, Wendy (Ed.)

1999 Women@Internet: Creating New Cultures in Cyberspace. Londres: Zed Books.

HARCOURT, Wendy

2010 Body Politics in Development. Londres: Zed Books

HARCOURT, Wendy y ESCOBAR, Arturo (Eds.)

2005 Women and the Politics of Place. Bloomfield, CT: Kumarian Press.

HATHAWAY, Mark y BOFF, Leonardo

2009 The Tao of Liberation: Exploring the Ecology of Transformation. Maryknoll, New York: Orbis Books.

HERNÁNDEZ, Rosalva Aída

2009 Indigeneity as a Field of Power: Possibilities and Limits of Indigenous Identities in Political Struggles. Presentada en la conferencia Contested Modernities: Indigenous and Afrodescendant Experiences in Latin America, Lozano Long Institute of Latin American Studies, University of Texas, Austin, Febrero 26-28.

HERNÁNDEZ, Rosalva Aída, (Ed.)

2008 Etnografias e Historias de Resistencia: Mujeres Indígenas, Procesos Organizativos y Nuevas Identidades Politicas. Mexico, DF: Publicaciones de la Casa Chata.

HOPKINS, Rob

2008 The Transition Handbook: From Oil Dependency to Local Resilience. White River Junction, VT: Chelsea Green Publishing.

HORNBORG, Alf

1996 Ecology as Semiotics: Outlines for a Contextualist Paradigm of Human Ecology. En: DESCOLA, Philippe y PÁLSSON, Gísli (Eds.), Nature and Society. 45-62. Londres: Routledge.

KAUFFMAN, Stuart

2008 Reinventing the Sacred. New York: Basic Books

KLEIN, Naomi

2007 The Shock Doctrine: The Rise of Disaster Capitalism. New York: Metropolitan Books

LANSING, Stephen

2006 Perfect Order. Recognizing Complexity in Bali. Princeton: Princeton University Press.

LATOUCHE, Serge

2009 Farewell to Growth. Cambridge: Polity Press. 
LASZLO, Ervin

2008 Quantum Shift in the Global Brain. How the New Scientific Reality Can Change Us and Our World. Rochester, VT: Inner Traditions.

LEYVA, Xochitl; BURGUETE, Araceli y SPEED, Shannon (Eds.)

2008 Gobernar (en) la Diversidad: Experiencias Indígenas desde América Latina: Hacia la Investigación de Co-Labor. México, DF: CIESAS.

LI, Tanie Murray

2007 The Will to Improve. Durham: Duke University Press.

LOHMANN, Larry

2006 Activism, Expertise, Commons. Development Dialogue 47: 149-181.

LONG, Norman; JINGZHONG, Ye y YIHUAN, Wang (Eds.)

2009 Rural Transformation Development. China in Context. Cheltenham, UK: Elgar.

LUGONES, María

2010 “The Coloniality of Gender”. En: MIGNOLO, Walter y ESCOBAR, Arturo (Eds.), Globalization and the Decolonial Option, 369-390. Londres: Routledge.

MACY, Joanna

2007 World as Lover, World as Self: Courage for Global Justice and Ecological Renewal. Berkeley: Parallax Press.

MACY, Joanna, and Molly BROWN

1998 Coming Back to Life. Practices to Reconnect Our Lives, Our World. Gabrilola Island, BC: New Society Publishers.

MAMANI, Pablo

2005 Geopoliticas Indígenas. El Alto: CADES.

2006 Territorio y Estructuras de Acción Colectiva: Microgobiernos Barriales. Ephemera 6(3): 276-286.

MANDER, Jerry y TAULI-CORPUZ, Victoria (Eds.)

2006 Paradigm Wars: Indigenous People's Resistance to Globalization. San Francisco: Sierra Club.

MARTÍNEZ ALIER, Joan

2009 Socially Sustainable Economic De-growth. Development and Change 40(6): 1099-1119.

MEZZADRA, Sandro

2007 Living in Transition: Toward a Heterolingual Theory of the Multitude. Eipcp multilingual webjournal. http://eipcp.net/transversal/1107/mezzadra/en

MCGREGOR, Andrew

2009 New Possibilities? Shifts in Post-Development Theory and Practice. Geography Compass 3: 1-15. 
MCMICHAEL, Philip

2006 Peasant Prospects in the Neo-Liberal Age. New Political Economy 11(3): 407-418.

2008 Peasants Make Their Own History, But Not Just as They Please.... Journal of Agrarian Change 8(2-3): 205-228.

MCMICHAEL, Philip, (Ed.)

2010 Contesting Development: Critical Stuggles for Social Change. Londres: Routledge.

MEDEIROS, Carmen

2005 The Right "To Know How to Understand": Coloniality and Contesting Visions of Development and Citizenship in the Times of Neo-Liberal Civility. Disertación doctoral, Departmento de Anthropología, City University of New York, The Graduate Center.

MIGNOLO, Walter

2000 Local Histories/Global Designs. Princeton: Princeton University Press.

MOONEY, Pat; ETC Group y What Next Project

2006 The What Next Report 2005-2035. Trendlines and Alternatives. Stockholm: Dag Hammarskjöld Foundation.

MOSSE, David

2005 Cultivating Development: An Ethnography of Aid Policy and Practice. Londres: Pluto Press.

2008 International Policy, Development Expertise, and Anthropology. Focal 52: 119-126.

MOSSE, David y LEWIS, David (Eds.)

2005 The Aid Effect: Giving and Governing in International Development. Londres: Pluto Press.

NONINI, Donald

2008 Is China Becoming Neoliberal? Critique of Anthropology 28(2): 145-176.

OSLENDER, Ulrich

2008 Comunidades Negras y Espacio en el Pacifico Colombiano. Bogotá: ICANH.

OSTERWEIL, Michal

2005 Place-based Globalism: Locating Women in the Alternative Globalization Movement. En: HARCOURT, Wendy y ESCOBAR, Arturo (Eds.), Women and the Politics of Place, 174-189. Bloomfield, CT: Kumarian Press.

PANITCH, Leo y GINDIN, Sam

2008 The Current Crisis: a Socialist Perspective. The Bullet. E-Bulleting 142, September 30. http://www.socialistproject.ca/bullet/bullet142.html. Último acceso: $10 \mathrm{de}$ agosto de 2010.

PATZI, Félix

2004 Sistema Comunal: Una Propuesta Alternativa al Sistema Liberal. La Paz: CEA. 
PIGEM, Jordi

2009 La Buena Crisis. Barcelona: Paidós.

POVINELLI, Elizabeth

2001 Radical Worlds: The Anthropology of Incommensurability and Inconceivability. Annual Review of Anthropology 30: 319-334.

POWELL, Dana

2010 Landscapes of Power. An Ethnography of Energy Development on the Navajo Nation. Disertación doctoral, Departmento de Antropología, University of North Carolina, Chapel Hill.

QUIJANO, Aníbal

2010 Buen Vivir: Entre el "desarrollo" y la des/colonialidad del poder. Manuscrito inédito, Lima.

RADCLIFFE, Sarah; LAURIE, Nina y ANDOLINA, Robert

2009 "Gender, Transnationalism, and Cultures of Development". En: Robert Andolina, Nina Laurie y Sarah Radcliffe, Indigenous Development in the Andes, 194-222. Durham: Duke University Press.

RAHNEMA, Majid y BAWTREE, Victoria (Eds.)

1997 The Post-Development Reader. Londres: Zed Books.

RASKIN, Paul, et al.

2002 Great Transitions. The Promise and the Lure of Times Ahead. Stockholm Environment Institute.

RIST, Gilbert

1997 The History of Development. From Western Origins to Global Faith. Londres: Zed Books.

ROJAS, Cristina y Shanon KINDORNAY

De próxima publicación "The Civilizing Missions and the Governing of Populations". En: H. Weber (Ed.), Politics of Development Encyclopedia. Londres: Routledge. En prensa.

SACHS, Wolfgang (Ed.)

1992 The Development Dictionary: A Guide to Knowledge as Power. Londres: Zed Books.

SACHS, Wolfgang y SANTARIUS, Tilman (Eds.))

2007 Fair Futures. Resource Conflicts, Security, and Global Justice. Londres: Zed Books.

SAHLE, Eunice

2010 World Orders, Development and Transformation. Londres: Palgrave Macmillan.

SANTOS, Boaventura de Sousa

2007 The Rise of the Global Left. The World Social Forum and Beyond. Londres: Zed Books. 
SCHAFER, Paul

2008 Revolution or Renaissance. Making the Transition from an Economic Age to a Cultural Age. Ottawa: University of Ottawa Press.

SHIVA, Vandana

2004 Monocultures of the Mind. Londres: Zed Books.

2005 Earth Democracy. Cambridge: South End Press.

2008 Soil, Not Oil. Environmental Justice in an Age of Climate Crisis. Cambridge: South End Press.

SIMON, David.

2007 Beyond Antidevelopment: Discourses, Convergences, Practices. Singapore Journal of Tropical Geography 28: 205-218.

SINHA, Subir

2008 Lineages of the Developmentalist State: Transnationality and Village India, 19001965. Comparative Studies in Society and History 50(1): 57-90.

SMITH, Brian Cantwell

1996 On the Origin of Objects. Cambridge: MIT Press.

STIGLITZ, Joseph

2006 Making Globalization Work. New York: W.W. Norton.

SUÁREZ NAVAZ, Liliana y HERNÁNDEZ, Rosalva Aída (Eds.)

2008 Descolonizando el Feminismo. Teoría y Practices Desde los Márgenes. Madrid: Ediciones Cátedra.

WOLFORD, Wendy

2010 This Land is Ours Now: Social Mobilization and the Meaning of Land in Brazil. Durham: Duke University Press.

YANG, Mayfair

2000 Putting Global Capitalism in its Place. Current Anthropology 41(4): 477-509.

ZAI, Aram

2007 "The Ambivalence of Post-Development: Between Reactionary Populism and Radical Democracy". En: ZAI, Aram (Ed.), Exploring Postdevelopment: Theory and Practice, Problems and Perspectives, 111-128. Londres: Zed Books.

ZIBECHI, Raúl

2006 Dispersar el poder. Los movimientos como poderes antiestatales. Buenos Aires: Tinta Limón. 